\title{
LAS PINTURAS RUPESTRES PALEOLITICAS DE LA CUEVA DE COVALANAS (RAMALES DE LA VICTORIA, CANTABRIA)
}

\author{
POR \\ ALFONSO MOURE ROMANILLO (*) \\ MANUEL GONZALEZ MORALES (*) \\ CESAR GONZALEZ SAINZ (*)
}

\begin{abstract}
RESUMEN El trabajo se inserta en una de las líneas de investigación del área de Prehistoria del Departamento de Ciencias Históricas de la Universidad de Cantabria, que tiene por objeto la documentación del arte rupestre de la región.

Las figuras paleoliticas de Covalanas forman un conjunto sincrónico y ordenado que emplea la técnica del tamponado y otros procedimientos pictóricos próximos a la misma. A partir del análisis estilistico de las figuraciones y de los signos, y de comparaciones con otros santuarios mejor fechados se estima que puede pertenecer a un momento avanzado del Solutrense Cantábrico.
\end{abstract}

ABSTRACT This work is included in one of the research lines of the Prehistory Area of the Department of Historical Sciencies (University of Cantabria), devoted to the documentation of regional rock art.

The palaeolithic figures at Covalanas are a sinchronic and ordered group, that uses the pointed-line technique and other pictorial procedures close to it. From the stylistic analysis of figures and signs, and from comparisons with other well-dated "sanctuaries", an advanced Solutrean date can be proposed for these paintings.

\section{INTRODUCCION}

\subsection{Planteamiento inicial}

En un trabajo anterior sobre las pinturas de la Cueva de La Haza (Moure, González Sáinz y González Morales, 1987) hemos señalado cómo muchos conjuntos de arte rupestre paleolítico conocidos desde principios de siglo estaban pendientes de una revisión actualizada, toda vez que los datos publicados de primera mano se habían recogido partiendo de supuestos teóricos, y con técnicas de documentación, propios de la época de los estudios originales. Está claro que los

(*) Dpto. de Ciencias Históricas (Area de Prehistoria). Universidad de Cantabria. 39071 Santander (Cantabria). 
cambios introducidos en los planteamientos metodológicos de la investigación sobre el arte parietal paleolitico obligan a una recogida exhaustiva de información directa a partir de los originales, mediante la utilización de las técnicas actualmente disponibles.

\subsection{Desarrollo de los trabajos}

Una de las primeras deficiencias que pudimos observar a la hora de abordar la revisión de las pinturas de la Cueva de Covalanas fue la carencia de un plano topográfico correcto de la misma. La topografia originalmente publicada, obra de Alcalde del Rio (1906: Est. I; Alcalde del Rio, Breuil y Sierra 1911: 15) era manifiestamente inexacta, como se podia comprobar en una simple observación visual en la cueva, y no permitia tener una idea precisa de la distribución de las figuras. Más aún, la segunda galería, situada al norte de la conocida por sus pinturas, era completamente diferente en su desarrollo. El detalle incluido en la obra de Leroi-Gourhan (1971: 277), por su carácter esquemático, tampoco subsanaba esta deficiencia. Por ello se acometió la tarea de realizar un nuevo plano completo, incluyendo todas las galerías de la cueva, con la posición exacta de las pinturas y otros restos de coloración.

Tras un primer reconocimiento de detalle se tomaron varias series de fotografías de las pinturas, tanto en diapositivas de color convencional como infrarrojas (iluminando con flash electrónico y lámparas de incandescencia). A partir de ellas se realizaron las reproducciones de las figuras, manteniendo el control de las dimensiones a través de las series de medidas tomadas in situ.

El trabajo, en su conjunto, ha sido desarrollado por un equipo del Area de Prehistoria del Departamento de Ciencias Históricas de la Universidad de Cantabria bajo la dirección de los firmantes de este articulo y con la participación de varios estudiantes y postgraduados adscritos al mismo. La topografía ha sido realizada por E. Torres Cosio, del Speleo Club Cántabro Universitario. La campaña fue financiada con una subvención de la Consejería de Cultura, Educación y Deporte de la Diputación Regional de Cantabria, que asimismo concedió el correspondiente permiso para los trabajos.

\subsection{Antecedentes}

Las pinturas de la Cueva de Covalanas fueron descubiertas por Hermilio Alcalde del Rio y Lorenzo Sierra ("uno a continuación de otro y separadamente», como precisa éste último) el 11 de septiembre de 1903, en el curso de una de sus campañas de exploración por la zona (Alcalde del Río 1906: 43; Sierra 1908: 140). Solamente dos dias después localizaron igualmente las pinturas de la Cueva de La Haza, y de la lectura de las referencias de estos autores conocemos que también exploraron con detenimiento la boca y galería de la Cueva del Mirón, bajo Covalanas, y otras cavidades de la zona de la hoy día llamada "Pared del Eco" (Alcalde del Río 1906: 46; Alcalde del Río, Breul y Sierra, 1911: 10-11; Sierra 1908: 140). Resulta interesante señalar que Sierra cita en ese mismo lugar que Covalanas era también conocida como Cueva de Las Herramientas, denominación hoy dia desaparecida de hecho.

Las referencias al posible yacimiento arqueológico de la entrada son poco precisas. Se habla de unas limitadas excavaciones con hallazgos similares a los de La Haza: algunos "cantos trabajados y utilizados" a los que se atribuye una cronología paleolítica, asi como restos de cerámica que evidenciaban la frecuentación de la cueva hasta épocas recientes (Alcalde del Río 1906: 46; Alcalde del Río, Breuil y Sierra, 1911: 22). Sierra, por su parte, es algo más preciso, señalando el hallazgo de algunos útiles líticos, restos óseos de oso, ciervo y jabalí, así como un fragmento de cerámica. En el Museo Regional de Prehistoria de Santander se conserva algo de material lítico y paleontológico -éste último identificado por A. Morales Muñiz, de la Universidad Autónoma de Madrid-, conjunto

T. P., 1990, n 47 
muy poco diagnóstico que no aporta nada a la cronologia de la ocupación. El relleno de la entrada de la cueva fue eliminado cuando se rebajo el nivel del suelo, y por tanto no és posible efectuar ninguna comprobación en este sentido.

Como en el caso de La Haza - y de otras cuevas de Cantabria - ese acondicionamiento supuso la radical alteración de la forma de acceso al interior de la cueva, que hoy se hace de pie, frente a los datos de los autores antiguos que señalaban la necesidad de penetrar encorvados (Alcalde del Rio, Breuil y Sierra, 1911: 15). Las intervenciones humanas recientes debieron incluir numerosos grafitos en las paredes, que fueron posteriormente sometidos, en fecha desconocida, a una limpieza tan minuciosa como destructiva: esta verdadera damnatio memoriae ha supuesto el piqueteado de zonas a veces amplias de la pared, en casos inmediatas a las propias pinturas; esos piqueteados y raspados incluso han sido "revocados" claramente con barro en algunas ocasiones para producir un efecto visual menos llamativo. Por otro lado, esta intervención ha sido netamente selectiva: se han eliminado los grafitos, pero también parece posible que lo havan sido los puntos o trazos de color negro y textura carbonosa que son frecuentes en toda la cueva, especialmente a la entrada, pero faltan por completo en la zona de las figuras. Los restos de pintura y trazos rojos, que aparentemente han sido respetados, pero no siempre. Por ejemplo, el signo A.4 ha sido borrado casi por completo. Por fortuna, nunca llegó a instalarse la luz eléctrica en Covalanas, pero el hecho de que el suelo natural de la zona de las pinturas se haya mantenido seguramente a la misma altura que estaba en el Paleolítico ha dejado las mismas a una altura completamente accesible, que si bien permite reconstruir hipotéticamente la perspectiva y efecto visual de los autores, ha supuesto también el inevitable roce de los visitantes con las figuras, lo cual es especialmente notorio en los salientes, o a la entrada del llamado divertículo (paredes C y D), donde el frotamiento ha hecho desaparecer parte de la pintura.

\section{DESCRIPCIONES}

\subsection{Localización}

La cueva de Covalanas está situada en la ladera del Monte Haza o Pando, que domina la margen derecha del río Calera, a unos centenares de metros aguas arriba de su confluencia con el Gándara. Sus coordenadas UTM son 30TVN 63418840, y su altitud sobre el nivel del mar de $320 \mathrm{~m}$. Los caracteres de la zona y sus yacimientos prehistóricos ya han sido descritos en otra ocasión anterior por nosotros (Moure, González Sáinz y González Morales 1987: 59-71 y mapa en Fig. 1; González Morales y Moure Romanillo, 1989), por lo cual no entraremos en más detalles al respecto. Solamente es importante señalar la estratégica posición que ocupan tanto El Mirón como Covalanas, dominando completamente el fondo del valle y la confluencia de los ríos, y a la vez el paso obligado por el . curso del Calera hacia Lanestosa y su estrecho valle, por donde aún corre el antiguo camino real hacia Burgos; en segundo lugar, su presencia como elemento destacado y perfectamente visible desde un amplio territorio, con lo que ello pudiera tener que ver con su elección como lugar donde realizar este grupo tan singular de representaciones pictóricas. Seguramente que no es ajeno a tal situación estratégica el que, según los autores antiguos, durante las acciones de las guerras carlistas (a las que Ramales de la Victoria debe la segunda parte de su nombre), la boca del Mirón se fortificara, llegándose a instalar en ella un cañón (Alcalde del Rio, Breuil y Sierra, 1911: 11) (Fig. 1 y Lám. Ia).

\subsection{Descripción de la cueva}

Covalanas está formada, en realidad, por dos galerías independientes que se abren a un porche 


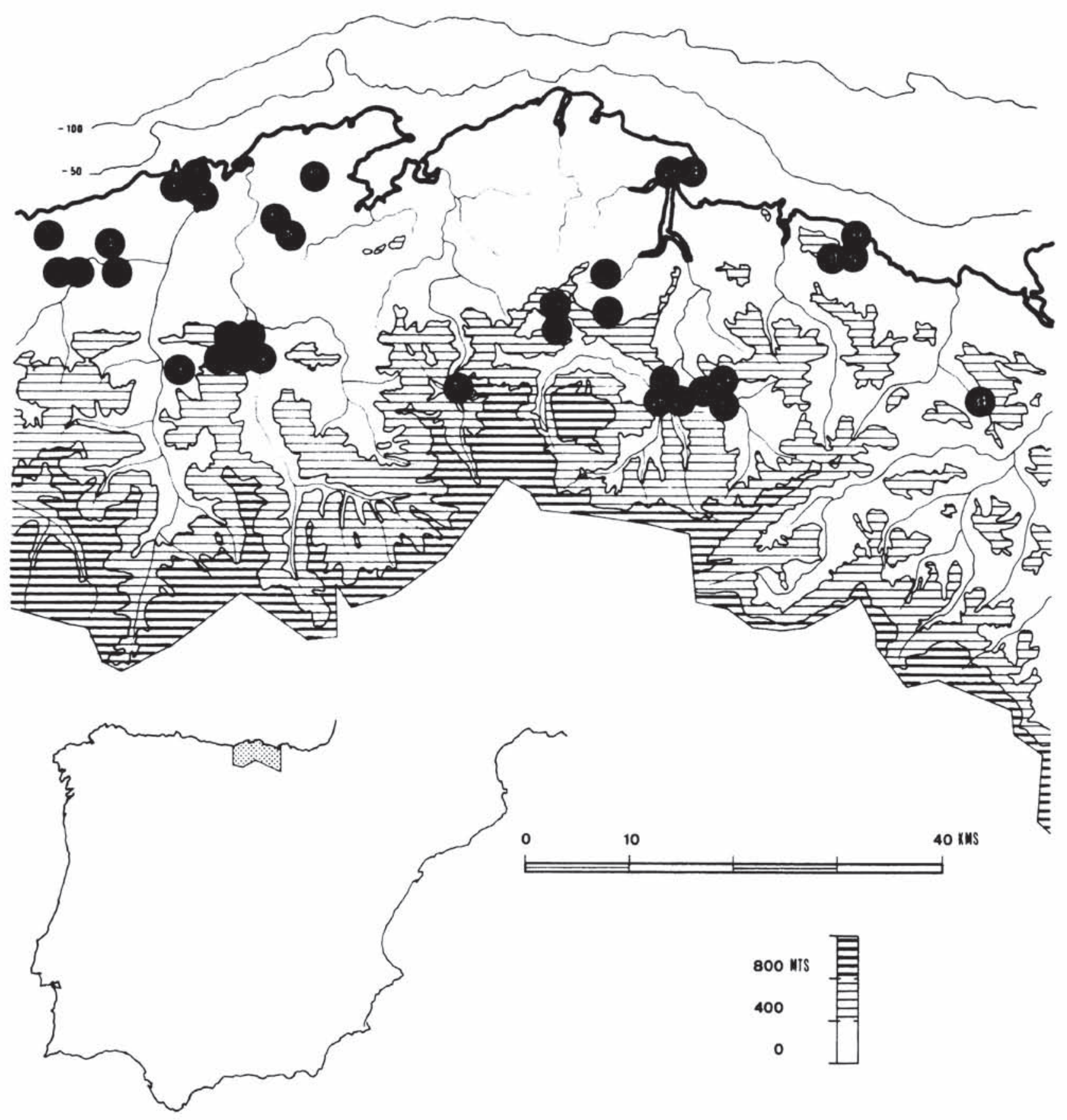

FIG. 1.- Distribución de los santuarios con arte rupestre en los sectores central y oriental de Cantabria y occidental del País Vasco: 1) Las Aguas; 2) El Linar; 3) El Perro; 4) Altamira; 5) La Clotilde; 6) Las Brujas; 7) La Pila; 8) Cudón; 9) Hornos de La Peña; 10) El Castillo; 11) Chimeneas; 12) Las Monedas; 13) La Pasiega; 14) La Flecha; 15) Santian; 16) El Pendo; 17) El Juyo; 18) Salitre; 19) Emboscados; 20) El Patatal; 21) El Otero; 22) Cobrantes; 23) San Carlos; 24) El Perro; 25) Cullalvera; 26) La Haza; 27) Covalanas; 28) Sotarriza; 29) Cova Negra; 30) Venta de La Perra; 31) La Lastrilla; 32) La Hoz; 33) El Cuco; 34) Arenaza. 
común de modestas dimensiones y visera poco profunda. A unas decenas de metros al Oeste se sitúa otro abrigo o covacho, algo más amplio, alineado con la dirección de la galeria de las pinturas, pero que no parece haber comunicado con ella, al menos en un pasado reciente (ver plano en Fig. 2). La galeria derecha en el sentido de entrada, o galería de las pinturas, tiene una trayectoria relativamente rectilinea, con variaciones moderadas en anchura. Su perfil transversal es disimétrico, predominando en altura la pared derecha de la galeria, en tanto que en la izquierda el techo se mantiene relativamente más bajo. El suelo, como antes se indicaba, ha sido rebajado en toda la zona de entrada, en ocasiones en más de un metro de espesor. Pero a medida que se penetra en la cueva se percibe en las marcas de depósitos arcillosos sobre las pareden que el nivel del suelo iba bajando rápidamente hacia el interior, hasta coincidir con la superficie actual a una veintena de metros de la entrada.

A los $70 \mathrm{~m}$. la galeria se estrecha considerablemente y se bifurca en dos conductos principales, que a su vez se ramifican nuevamente determinando una especie de laberinto final donde buena parte de las gateras son infranqueables, y por supuesto de proporciones mucho más reducidas que la galeria de entrada. En la pared izquierda, justo antes del estrechamiento, se sitúa en un conducto paralelo, a un nivel algo superior con respecto al suelo de la galería, que es el usualmente denominado "divertículo».

La cueva presenta escasas formas de reconstrucción litoquímica: son de destacar algunas columnas aisladas en la zona inicial de la galería y algunas banderas en las zonas altas, junto a los techos. Las formaciones parietales tampoco son muy abundantes, pero es evidente que algunas neoformaciones han cubierto parcialmente las pinturas paleolíticas.

La galería izquierda difiere sensiblemente en su desarrollo del plano publicado por Alcalde del Rio, sobre todo en lo que se refiere a la orientación de la amplia galería del fondo. En toda ella son más frecuentes las formaciones e igualmente se aprecian en las paredes restos de trazos negros, como los que abundan en la zona inicial de la galeria de las pinturas. No entramos en una descripción más detallada de la galeria por caer fuera de los objetivos del presente trabajo.

\section{LAS REPRESENTACIONES RUPESTRES}

\subsection{Repartición topográfica}

Hay dos tipos de evidencias parietales en Covalanas: de una parte las representaciones paleolíticas, sistemáticamente en color rojo; de otro lado, son muy abundantes los restos de coloración negra, que se reducen a pequeños trazos con carbón vegetal, puntos y líneas de escasa longitud.

La dispersión topográfica de unos y otros restos es bien distinta. Las representaciones paleolíticas . se concentran esencialmente en un área de unos $12 \mathrm{~m}$. de longitud, sobre la galería principal y un divertículo anejo de orientación paralela a esa galería (Fig. 3). Se trata de un área profunda, casi terminal, cuyo inicio se sitúa a unos $65 \mathrm{~m}$. de la entrada a la cavidad. Fuera de este área, tan sólo encontramos una posible línea cérvico-dorsal (D. 1), y algunos restos de color rojo muy perdidos (Fa), en ambos casos, situados en zonas terminales, de acceso más difícil. Los restos de coloración negra por el contrario, se distribuyen más aleatoriamente por toda la cavidad, incluida la galería izquierda, donde no hay representaciones rojas.

\subsection{Descripción de las pinturas paleolíticas}

Seguiremos un orden meramente topográfico, comenzando por las representaciones de la pared

T. P., $1990, \mathrm{n}^{\circ} 47$ 

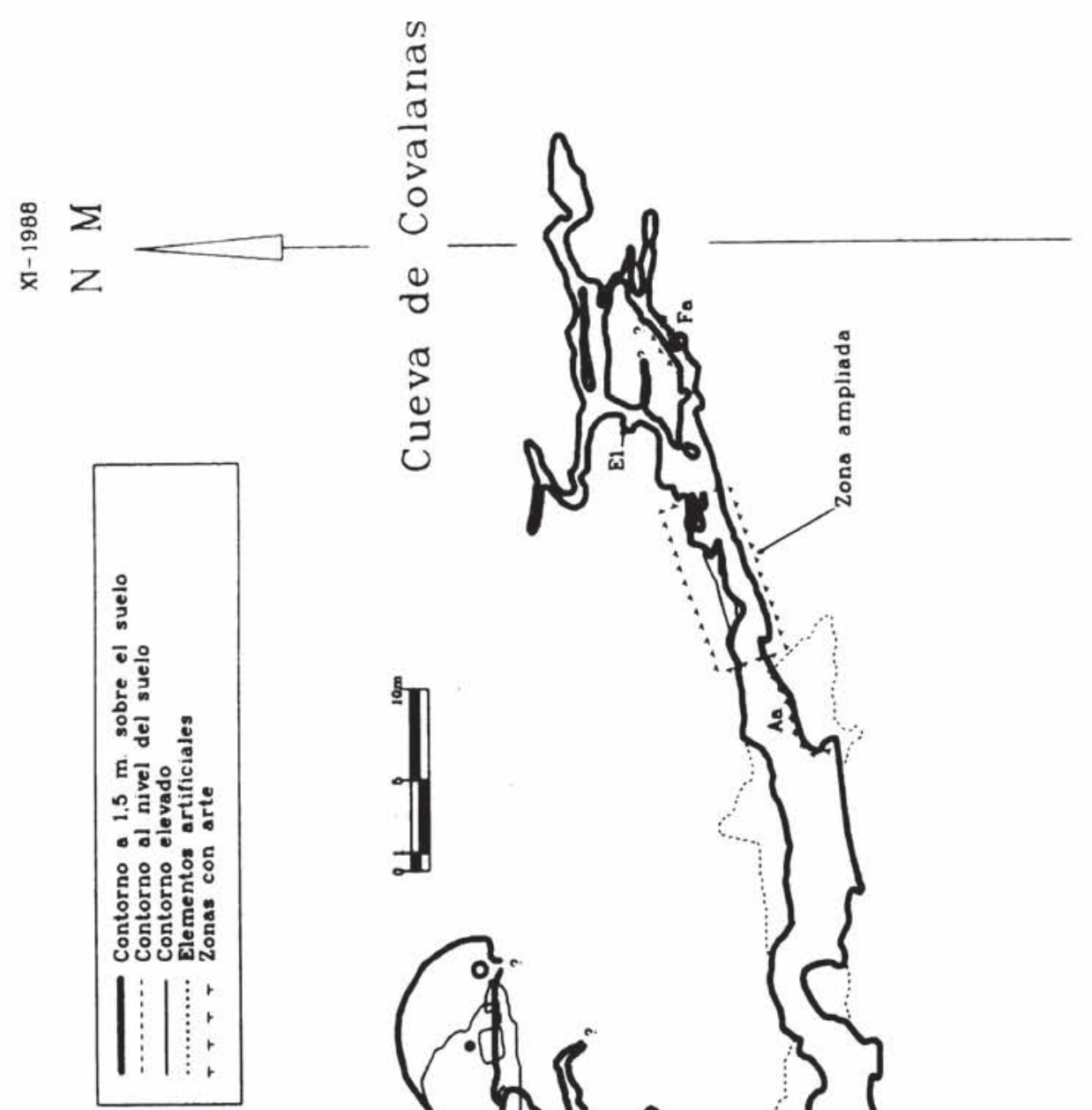

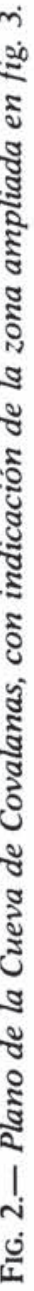




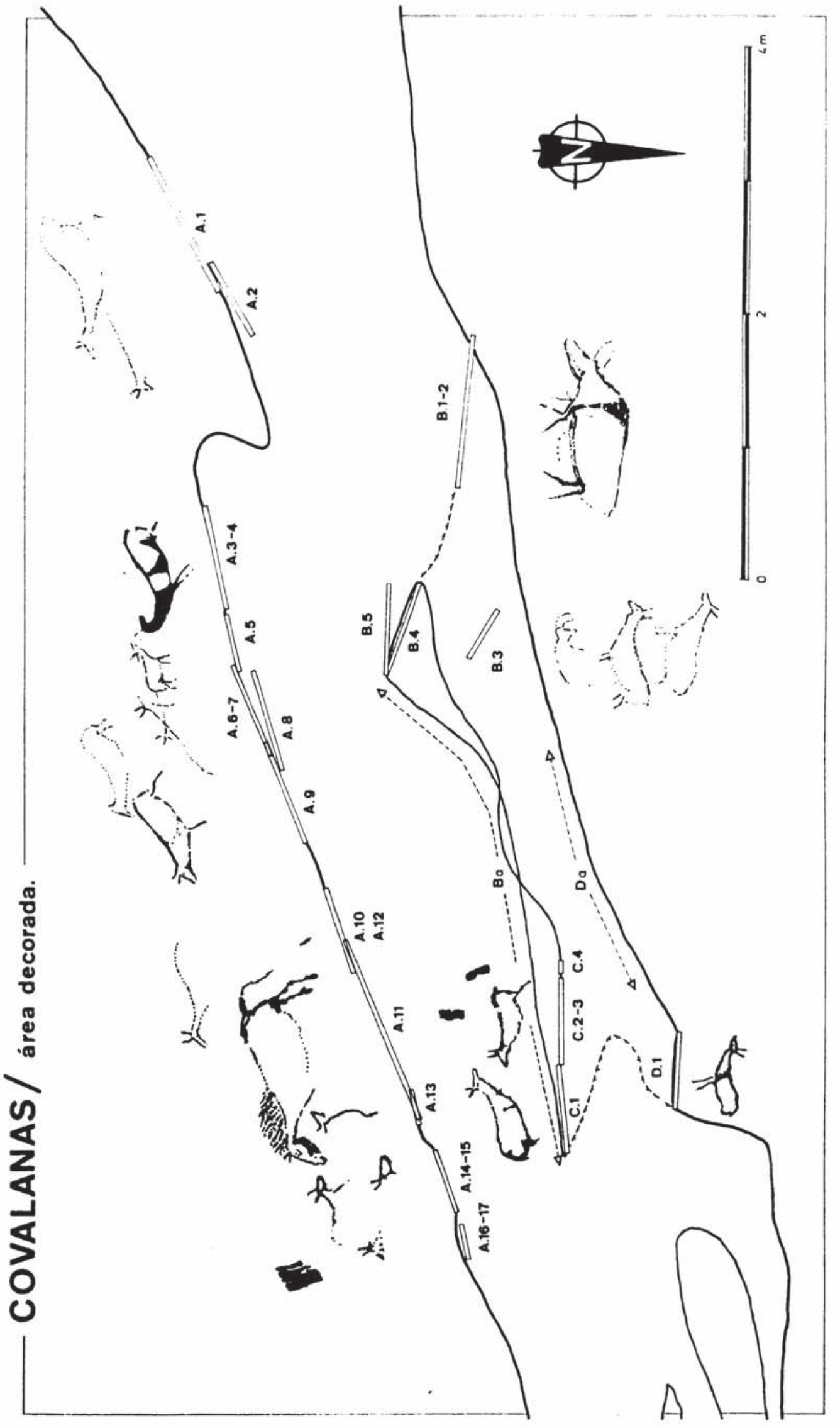

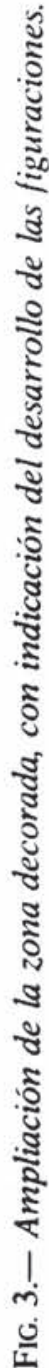

T. P., $1990, \mathrm{n}^{2} 47$ 
derecha de la galeria principal (A), desde el punto más cercano a la entrada de la cueva. Continuamos con las figuras de la pared izquierda (B), y luego con las del diverticulo abierto en el lateral izquierdo de la galeria principal (Paredes C y D). Por último se incluyen algunas representaciones en sectores de fondo $(E$, sobre una ramificación lateral muy estrecha, y $F$, al fondo de la galeria principal).

Hemos numerado consecutivamente las representaciones de cada una de esas paredes o zonas (A.1, 2, 3...), reservando letras para las evidencias parietales más dificiles de interpretar, como las manchas informes, los restos minimos de coloración etc. (A.a, b...).

Pared A. / (Panel primero) (Fig. 4 y Lám. Ib)

A. a. Pocos metros antes de llegar a la zona de representaciones, puede observarse toda una serie de restos desvaídos de pintura roja en una concavidad de la pared derecha. Aunque no puede excluirse que se trate de restos de una figuración, más bien parecen pruebas de los utensilios y colorantes usados, o restos de su limpieza.

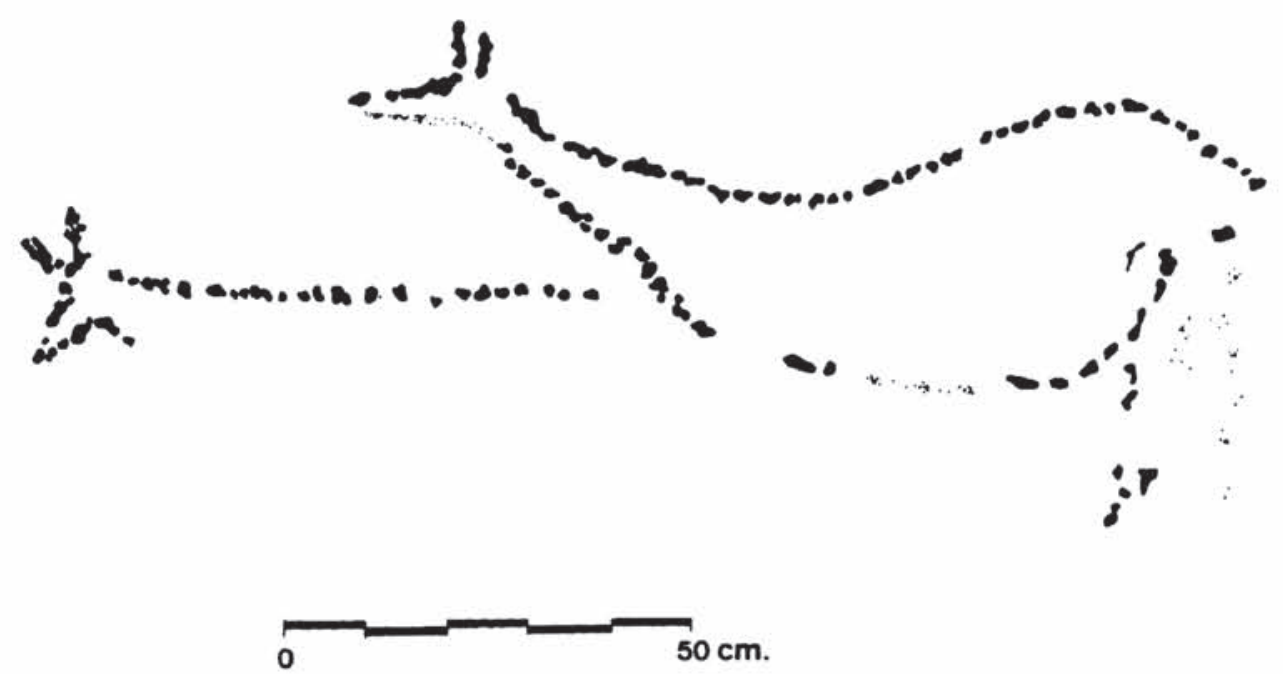

FIG. 4.- Ciervas A.I y A.2, constituyendo el primer panel de la pared derecha.

A.1 Cierva en rojo, de contorno completo en origen. Actualmente se sigue bien la cabeza con dos orejas, línea cérvico-dorsal hasta la cola, cuello, línea pectoral y ventral. De las extremidades anteriores, que aprovechan los bordes de una concavidad natural, no quedan sino tenues restos de pintura. De otro lado, la línea del vientre se ha hecho coincidir con el limite entre dos zonas de la roca-soporte de diferente textura y coloración: más grisácea y lisa en la concavidad donde se aloja el vientre, más rugosa y amarillenta en el exterior de la figuración.

El trazo de contorno es tamponado yuxtapuesto en casi toda la figura, con mínima distancia entre puntos en la cabeza, orejas y cuello. En el otro extremo, en la grupa, los puntos se han separado algo más. Por último, la línea ventral se ha realizado en tamponado convencional, o discontinuo. En composición destaca la cara apuntada, las orejas en prolongación de líneas frontal y cervical, o el cuello-muy alargado. L. max.: 117; L. frontal: 17; Alt. en la cruz: 48. Presenta raspados recientes en la zona ventral.

T. P., $1990, \mathrm{n}^{2} 47$ 
A.2. Cierva inacabada en rojo. Se compone de cabeza apuntada, orejas en $\mathrm{V}$, línea cérvicodorsal e inicio de la pectoral. El trazo es tamponado yuxtapuesto en toda la parte anterior, y discontinuo en la zona dorsal. Destaca el trazo ligeramente ampliado de la linea frontal, a la altura del ojo. L. max.: 72; L. frontal: 11.

Frente a la cierva anterior (A.1, en el mismo panel), cabe destacar la correlación entre lo inacabado de A.2 y su trazo tamponado discontinuo más claro en zona dorsal. Se advierten limpiezas de la pared junto a líneas de cabeza y cuello.

\section{Pared A / (Panel segundo) (Fig. 5 y Lám. IIa)}

A.3. Cierva completa en rojo. Es una de las figuraciones más complejas de Covalanas, tanto en su composición - la cierva vuelve la cabeza hacia atrás, y el interior del cuerpo está muy articuladocomo en las técnicas empleadas - tintas planas, distintos tipos de trazos pintados, y grabado-. En origen parece que estuvo completa, pero hoy son difíciles de apreciar la oreja izquierda y los cuartos traseros.

En principio todo el contorno se ha realizado en trazo tamponado yuxtapuesto muy estrecho, casi continuo. Sólo encontramos tamponado convencional en la extremidad anterior más adelantada. En algunas zonas se aplicó además tinta plana, muy intensa en la cabeza y parte anterior del cuello;

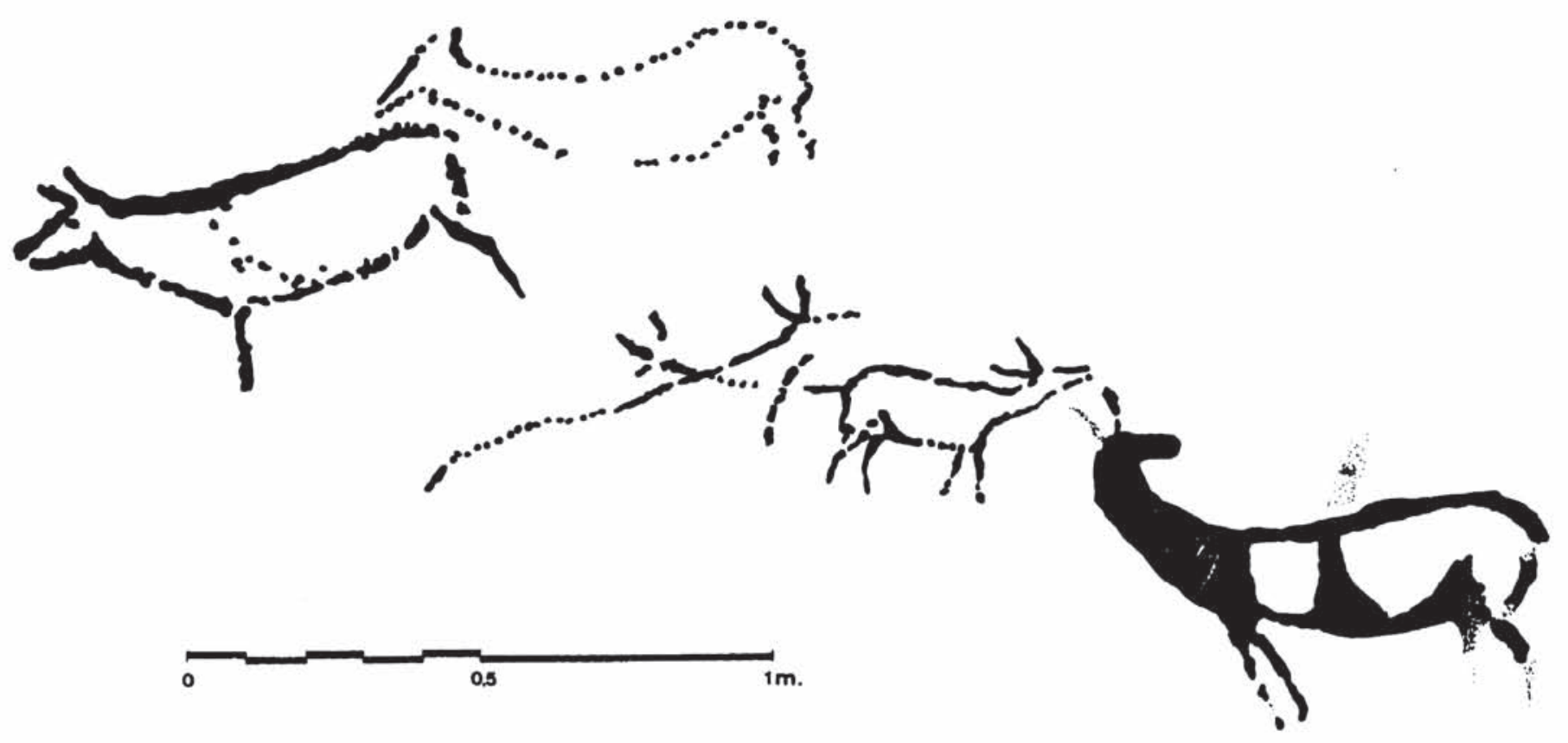

FIG. 5.- Segundo panel de la pared derecha (figuras A.3 a A.9).

más abajo, se advierte hoy una tinta plana muy diluida (que puede estar corrida), y algunas bandas más intensas en la parte baja del cuello. También es muy intensa una banda de despiece desde los cuartos anteriores hasta la cruz. Por último se realizó otra banda en tinta plana desde el lomo al vientre, donde es más ancha. Otra modalidad técnica, difícil de distinguir de lo anterior, son los trazos ampliados en anchura de los cuartos anteriores, y de la parte interna de la extremidad posterior izquierda de la cierva (representada algo adelantada para dar profundidad a la figuración). 
Por último, se ha precisado la linea de la barbilla y parte del cuello con trazos grabados simples repetidos. También este último hecho permite relacionar esta figura con varias ciervas de la Galería A de La Pasiega. L. max: 79; L. frontal: 11; Alt. en cruz: 37.

Está muy alterada por lavados (sobre el lomo, en toda la zona ventral de la figura y en sus cuartos traseros), y repicados (en cuartos traseros).

A.4. Restos de pintura roja sobre el lomo de cierva A. 3, de unos $12 \mathrm{~cm}$. de longitud máxima conservada. Hoy están casi borrados por raspados y limpiezas varias de la pared. En el calco de $\mathrm{H}$. Breuil parece tratarse de un signo de tipo cuadrangular alargado, en tinta plana.

A.5. Cierva completa en rojo. Todo el contorno en trazo tamponado yuxtapuesto, indicándose dos orejas en V, la nuez sobre la línea del cuello, y el inicio de la cola. Las extremidades, como en cierva A.3, están tratadas de forma distinta. Las anteriores son simples lineas en V invertida, mientras que en los cuartos traseros se ha empleado el trazo ampliado en el contorno de la pata que está en segundo plano -y adelantada - para dar profundidad a la figuración. L. max: 45; L. frontal: 9; Alt. en cruz: 23 (Lám. IIb).

Se advierten raspados por todas partes alrededor de la figura, y también en su interior. Además, una línea negra - probablemente de carburo- se superpone a una de las patas delanteras.

A.6. Cierva en rojo compuesta de línea frontal y pectoral, dos orejas en $\mathrm{V}$, y línea cérvico-dorsal completa. El trazo es tamponado yuxtapuesto en orejas y zona cervical, y discontinuo en el resto.

Toda la parte superior está muy afectada por raspados y limpiezas de la pared. Es probable que en origen la línea frontal fuera más nítida $-\mathrm{y}$ en tamponado yuxtapuesto-, e incluso que se marcara la linea de la barbilla como indica el calco de Breuil, que hoy no se aprecia. L. max.: 82; L. frontal: 10.

A.7. Cierva en rojo, compuesta de línea frontal de la cara muy perdida, dos orejas en $\mathrm{V}$ en tamponado yuxtapuesto, y línea cérvico-dorsal en tamponado discontinuo. El lomo se cruza con el de la figura A.6, pero no se puede apreciar el orden de ejecución. L. máx. conservada: 35.

La figura está afectada por las mismas zonas de raspado que citábamos en cierva A.6, particularmente toda la zona frontal de la cara.

A.8. Cierva en rojo de contorno completo, a excepción de las patas delanteras que no se indicaron. La línea frontal de la cara, orejas y nuca en tamponado yuxtapuesto. El resto de la figuración (línea cérvico-dorsal, grupa, cuartos traseros, línea ventral, pectoral y barbilla) en tamponado discontinuo muy líquido. Además de la nuez, destaca la realización de las orejas, muy cortas, mediante prolongación de lineas frontal y cervical.

Cabe destacar de nuevo la jerarquización de zonas a representar que se repite en Covalanas y otras cavidades cantábricas. $\mathrm{O}$ cómo la ausencia, en este caso, de extremidades delanteras, se correlaciona con el mejor acabado de las traseras en aquellas figuras que presentan las cuatro extremidades. De igual forma, el mejor acabado técnico de la cabeza, frente a la zona dorsal o ventral. L. max.: 177; L. frontal: 16.

La conservación de la figura es bastante buena, aunque también aquí se observamos alteraciones: un tracito negro pintado en la zona de la escápula, e inmediatamente debajo, una zona picada.

A.9. Cierva completa en rojo, de realización técnica compleja. Al tamponado yuxtapuesto de casi toda la figura escapan dos líneas en tamponado discontinuo que articulan el interior de la figura partiendo de la cruz, o el trazo simple empleado en los cuartos traseros, que ha sido ampliado en determinadas zonas (para conformar el codo por ejemplo), o restringido en otras (en el

T. P., 1990, $\mathrm{n}^{2} 47$ 
pie, ligeramente apuntado). También encontramos un trazo simple continuo, en rojo diluido, en la grupa de la cierva: sobre ese trazo previo se punteó el contorno con tamponado discontinuo. El tamponado yuxtapuesto de la mayor parte del contorno también se amplia en determinadas partes, tratando de conseguir un cierto volumen (así en la zona cervical y dorsal, o en la barbilla) (Lám. IVa).

Además del despiece escapular, destaca la realización del ojo - un punto simple-, u otros detalles como el adelantamiento de las dos orejas, que son prolongación en ángulo de líneas frontal y cervical. L. máx.: 78; L. frontal: 14; Alt. en cruz: 40.

Desgraciadamente parece darse una cierta correspondencia entre complejidad técnica o grado de acabado de la figuración, e intensidad de su alteración posterior. En la figura que tratamos se aprecia un punto negro de $3 \mathrm{~mm}$. en la cruz, por encima de la pintura roja (es el mismo pigmento de las representaciones "esquemático-abstractas»). También hay inevitables limpiezas a base de raspados en el interior del cuerpo, en los cuartos anteriores y en la zona de la cabeza, y auténticos repicados en la grupa. Con presumible posterioridad a estas limpiezas de pintadas, se han ejecutado algunas manchas con carburo sobre el morro y barbilla.

Pared A / (Panel tercero) (Fig. 6 y Lám. IIIa).

A.10. Cierva en rojo muy sencilla. Consta de línea frontal de la cara, dos orejas en $\mathrm{V}$, y línea cérvico-dorsal completa. Por su parte inferior se ha detallado la barbilla, parte inferior del cuello y linea pectoral. Casi toda la figura se realizó en tamponado discontinuo; tan sólo es yuxtapuesto claro en el inicio de las orejas y zona de la nuca. Como en otras figuras, la separación de los puntos es mayor en el dorso y grupa (Lám. IIIb).

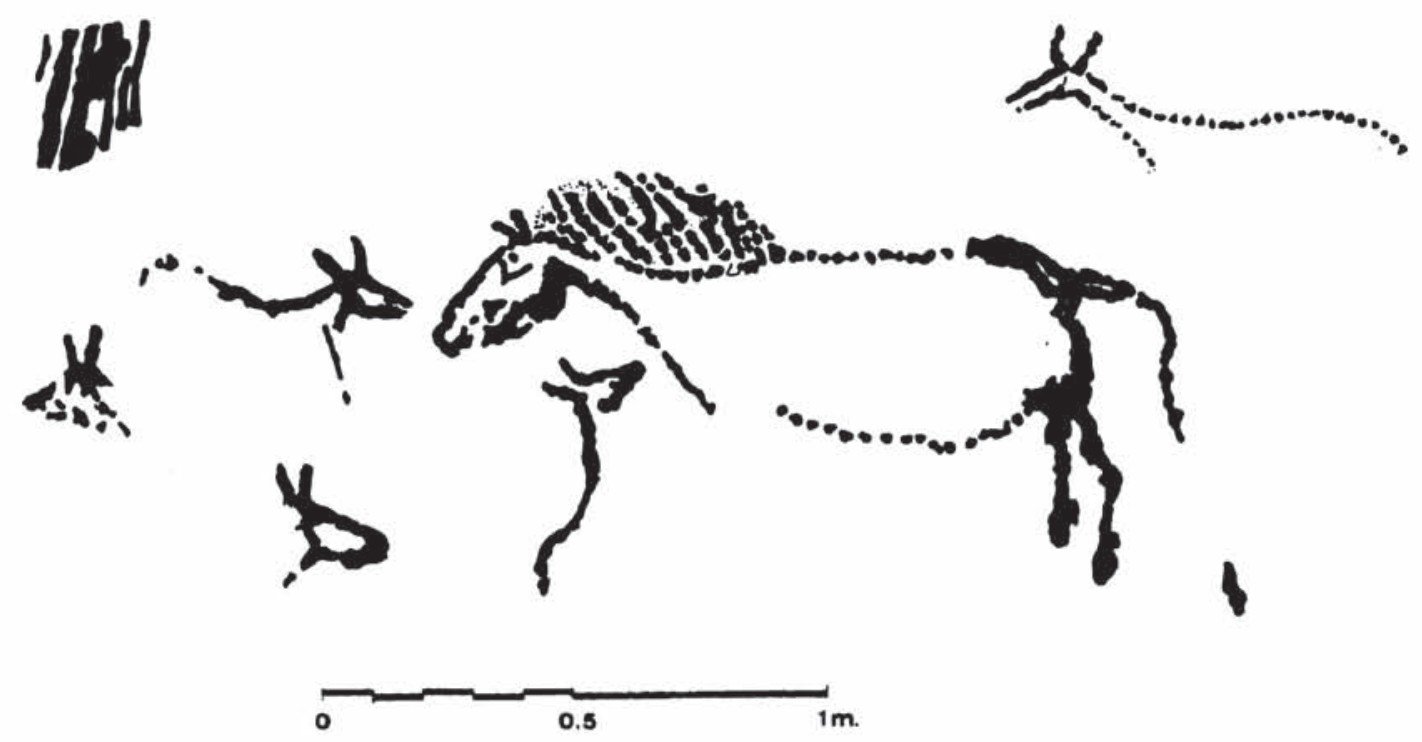

FIG. 6.- Tercer panel de la pared derecha (figuras A.10 a A.17).

La cabeza presenta una cierta complejidad, quizá por ser la zona más alterada de la figuración. Hay un manchón rojo que pudiera interpretarse como ojo; también una línea roja muy fina que sobresale de la figura desde la barbilla. Por último se ha indicado la nuez. L. máx: 107; L. frontal: $16 \mathrm{~cm}$. 
La figura está muy alterada. De una parte, las lineas de la cara están algo perdidas por pequeñas escorrentias en esa zona. De otro lado, se advierten zonas repiqueteadas por debajo de la cara, o raspadas sobre la misma grupa del animal. Por último, hay algunos grabados modernos cruzando el lomo de la figura, o marcas de dedos con arcilla sobre la misma línea pectoral.

A.11. Caballo en rojo completo, a excepción de los cuartos delanteros, no indicados. La cabeza y casi todo el contorno se realizó con tamponado vuxtapuesto, ampliado hasta formar casi una tinta plana en determinadas zonas. Sólo en la línea dorsal y en la ventral se empleó el tamponado discontinuo (Lam. IIIb).

La cabeza está muy detallada, aunque la pintura se ha corrido en algunas zonas. Se indica la boca, el ojo - un punto resaltado por dos trazos en ángulo en su parte inferior-y dos orejas en V. También se ha realizado una línea de despiece longitudinal, desde el labio inferior al inicio del cuello, que modula la forma del masetero: en esa zona se aúnan en trazo ampliado esta linea de despiece y la inferior del contorno. A partir de aqui parten en ángulo la línea inferior del cuello -ligeramente ampliada en su inicio- y la pectoral.

Sobre la linea cervical se ha representado una espléndida crinera mediante trazos en tamponado generalmente discontinuo, casi "hachures" en algunos casos. Crinera y línea cervical finalizan en la cruz, bien marcada. En la grupa e inicio de la cola se ha empleado un doble trazo paralelo. La cola se prolonga en trazo tamponado yuxtapuesto simple, rodeando un pequeño pilón estalagmítico. Los cuartos traseros, por último, se han realizado mediante tamponado yuxtapuesto ampliado. En ambas extremidades se detalla el casco redondeado y los dedos posteriores atrofiados de la pezuña. L. máx.: 139; L. frontal: 22.

Prescindiendo ya de detallar las zonas donde se han efectuado «limpiezas», se advierten precipitaciones blancuzcas de carbonatos sobre la crinera, o cierta acumulación de hollín en la parte posterior, donde la pared forma repisa. A otras causas, desde luego, responde un trazo en pintura plástica negra sobre la pata posterior.

A.12. Pequeño trazo rojo en tamponado yuxtapuesto, ligeramente ampliado en su zona medial. Se sitúa a la derecha de los cuartos traseros del caballo A.11, y aunque su orientación es vertical, no parece tratarse del extremo de la cola del caballo, de la que está demasiado alejado.

A.13. Cierva incompleta en rojo en posición vertical. Consta de una cabeza apuntada, dos orejas en V y línea cérvico-dorsal; todo ello en tamponado muy yuxtapuesto, difícil de distinguir del trazo simple y único.

Cabe resaltar en la cabeza la ampliación del trazo de la barbilla, o un trazo muy perdido en la zona del ojo. De otra parte, parece haberse aprovechado una depresión natural de la pared como línea anterior del cuello y pectoral. L. máx.: 40; L. frontal: 10. La conservación en este caso es prácticamente perfecta.

A.14. Cierva incompleta en rojo, compuesta de cabeza, dos orejas en V desplazadas hacia atrás y línea cérvico-dorsal, todo ello en tamponado yuxtapuesto. El trazo está algo ampliado en la barbilla, empalmando con la nuca y separando por tanto la cabeza del tronco, a manera de "despiece".

La conservación es muy deficiente. En la grupa, la línea roja está recortada por concrecciones calcáreas blanquecinas. En la cabeza y por debajo de ella, se advierten restos de pintura roja deslavados desde arriba. Por debajo del cuello puede observarse una línea roja que parece responder a la canalización del pigmento lavado en la figuración. Por último deben indicarse algunos restos de pintura roja a unos $15 \mathrm{~cm}$. por encima del lomo, muy afectados por concreciones y picados de la pared. L. máx.: 45 ; L. frontal: $10 \mathrm{~cm}$. 
A.15. Cabeza de cierva en rojo. Quizá en origen la figuración estuvo más completa, pero la zona que correspondería al tronco del animal está muy afectada por concrecciones. La organización de la cabeza y el procedimiento técnico son idénticos al de la figura situada más arriba (A.14); orejas en V, morro abierto, y un trazo separando la cara del cuello, todo ello en trazo vuxtapuesto estrecho.

La conservación de la cabeza es buena, pero la figura está afectada por concreciones ya en la parte posterior del cuello. Debe indicarse un trazo doble, que delimita el exterior de la oreja más adelantada, probablemente grabado en nuestros dias. L. máx.: 25; L. frontal: 14.

A.16. Cabeza de cierva en rojo, muy alterada por formaciones estalagmiticas superpuestas. La figuración consta de una línea frontal de la cara, dos orejas en $\mathrm{V}$, inicio de la línea cervical y parte anterior del cuello. La cabeza pudo estar más completa, pero la zona de la barbilla está totalmente concrecionada. L. máx. conservada: 19; L. frontal: $9 \mathrm{~cm}$.

A.17. Signo de forma rectangular en tinta plana roja, de 18,5 por $31 \mathrm{~cm}$. aproximadamente. Se encuentra muy afectado por precipitaciones estalagmíticas blancuzcas verticales, sobre todo en su parte inferior.

Pared B. / (Panel cuarto) (Fig. 7 y Lám. IVb)

B.1. Reno en rojo, prácticamente completo si incluimos la forma de un accidente natural aprovechado para situar el lomo, la grupa e inicio de la cola. La cabeza es de perfil cuadrangular, con una línea de despiece en maxilar inferior y ojo yuxtapuesto a la línea frontal de la cara; las astas se ha representado muy cortas, mediante dos líneas casi paralelas. También se ha realizado un despiece ventral, y otro dorsal de forma triangular, desde la zona de la cruz a las extremidades anteriores. Los cuartos anteriores y posteriores por su parte se sitúan en dos planos.

Técnicamente, toda la figura se realizó mediante tamponado yuxtapuesto, a excepción de las líneas de despiece facial y ventral, en tamponado convencional. De otro lado, se aprecia una ligera ampliación del trazo, como en otras figuras de Covalanas, en la línea de la barbilla y frontal de la cara, o en la extremidad posterior que está en segundo plano. Por último, se han realizado algunas líneas rojas muy finas, simples y continuas, junto al comienzo de los cuartos anteriores, sobresaliendo hacia el exterior. L. máx.: 193; L. frontal: 25; alt. en cruz: 75.

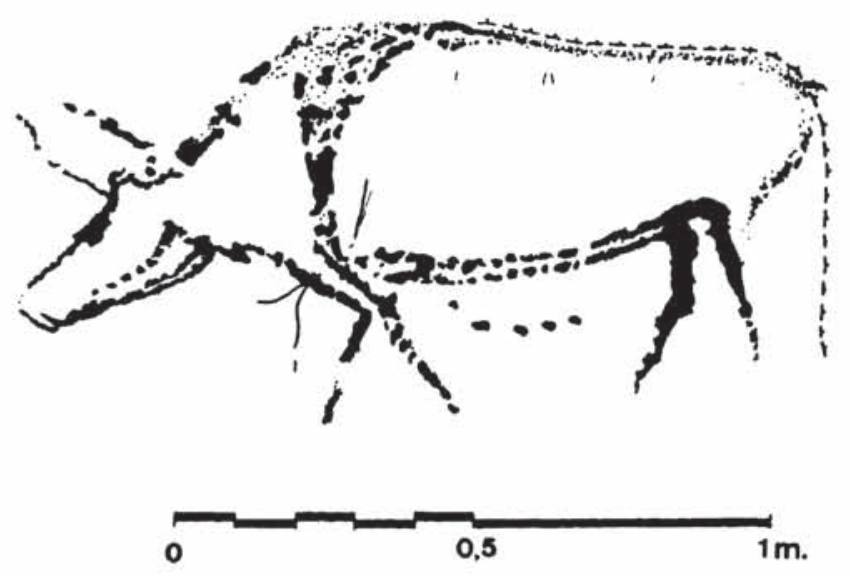

FIG. 7.- Posible representación de reno ý linea de puntos, indicadas con números B.1 y B.2. 
B.2. Agrupamos aqui toda una serie de puntos situados en las inmediaciones del reno descrito. De una parte, son muy claros cinco puntos rojos situados bajo el vientre de esa figura. Algo más tenues, se localizan algunos pequeños puntos o restos de pintura frente a la cara de la figuración.

Pared B. / (Panel quinto) (Fig. 8 y Lám. Va)

B.3. Posible bóvido en rojo, realizado en posición invertida. Consta de una cabeza apuntada, dos cuernos incurvados hacia abajo, linea cérvico-dorsal, y parte anterior de la pectoral. Sobre todo estas dos últimas están muy alteradas por concreciones. Todos los trazos en tamponado yuxtapuesto. L. máx. conservada: 60; L. frontal: 11.

B.4. Cierva en rojo completa. Se ha representado una cara apuntada y cerrada, con un punto simple como ojo. Las dos orejas son prolongación de la linea frontal y de la cervical. Además, consta de línea cérvico-dorsal prolongada en cola corta, nalga, línea pectoral, con una nuez muy marcada en el cuello, cuatro extremidades rectilineas, y dos lineas paralelas (en despiece) en la zona ventral.

Casi toda la figura se realizó mediante trazo tamponado yuxtapuesto. En la zona dorsal incluso se ha repasado con un doble trazo. Sólo en el vientre se empleó el tamponado convencional. L. máx.: 85; L. frontal: 16; Alt. en la cruz: $31 \mathrm{~cm}$.

Está muy desvaida la pintura de la zona ventral y sobre todo de los cuartos traseros. Un trazo de pintura negra plástica sobre una de las patas anteriores, es quizá la alteración humana más reciente, junto a raspados sobre la pared entre B.3. y B.4.

B.5. Cierva completa en rojo. Consta de cabeza apuntada, abierta en su parte anterior, dos orejas prolongando las lineas frontal y cervical, linea cérvico-dorsal completa - con la cruz indicaday prolongada en una cola muy corta, línea de nalga y dos extremidades traseras. Además, línea pectoral, extremidades anteriores rectilineas $-\mathrm{y}$ entrecruzadas en su inicio- y línea ventral.

El trazo es tamponado yuxtapuesto en cabeza y zonas próximas: orejas, cerviz y parte anterior del cuello. El resto en tamponado convencional. L. máx.: 84; L. frontal: 14; Alt. en cruz: $37 \mathrm{~cm}$. Presenta raspados recientes en la zona ventral.

B.a. Un punto de color rojo oscuro, nítido, a $154 \mathrm{~cm}$. del suelo y a 185 a la derecha de la cierva B.5. A partir de ahí, y más a la derecha, se ven marcas difusas en rojo alteradas por el piqueteado. Al extremo elevado, en el reborde que delimita la pared, manchas rojizas de mayor extensión en las oquedades, dado que es zona de arroyada de agua, etc. En horizontal, a $265 \mathrm{~cm}$. del punto, a la derecha, y a $169 \mathrm{~cm}$. del suelo hay un par de posibles restos de puntuaciones rojizas y a $23 \mathrm{~cm}$. por encima otro resto de pintura roja, y a $40 \mathrm{~cm}$., justo al borde del saliente de la pared, un resto algo mayor, pero también muy difuso, de pintura roja.

Zona C. / (Panel sexto) (Fig. 9 y Lám. VIa)

C.1. Cierva completa en rojo. Si excluimos una barbilla en tamponado convencional, todo el contorno se realizó en tamponado yuxtapuesto, algo ampliado en los cuartos traseros. Destacan en la composición las dos orejas en $\mathrm{V}$, o la indicación del ojo - un punto simple-, de la nuez, y de la cola, que prolonga la línea dorsal. Igualmente, la prolongación de la línea de barbilla para dibujar el maxilar, o un trazo rojo situado sobre el inicio de las extremidades delanteras que no sabemos 


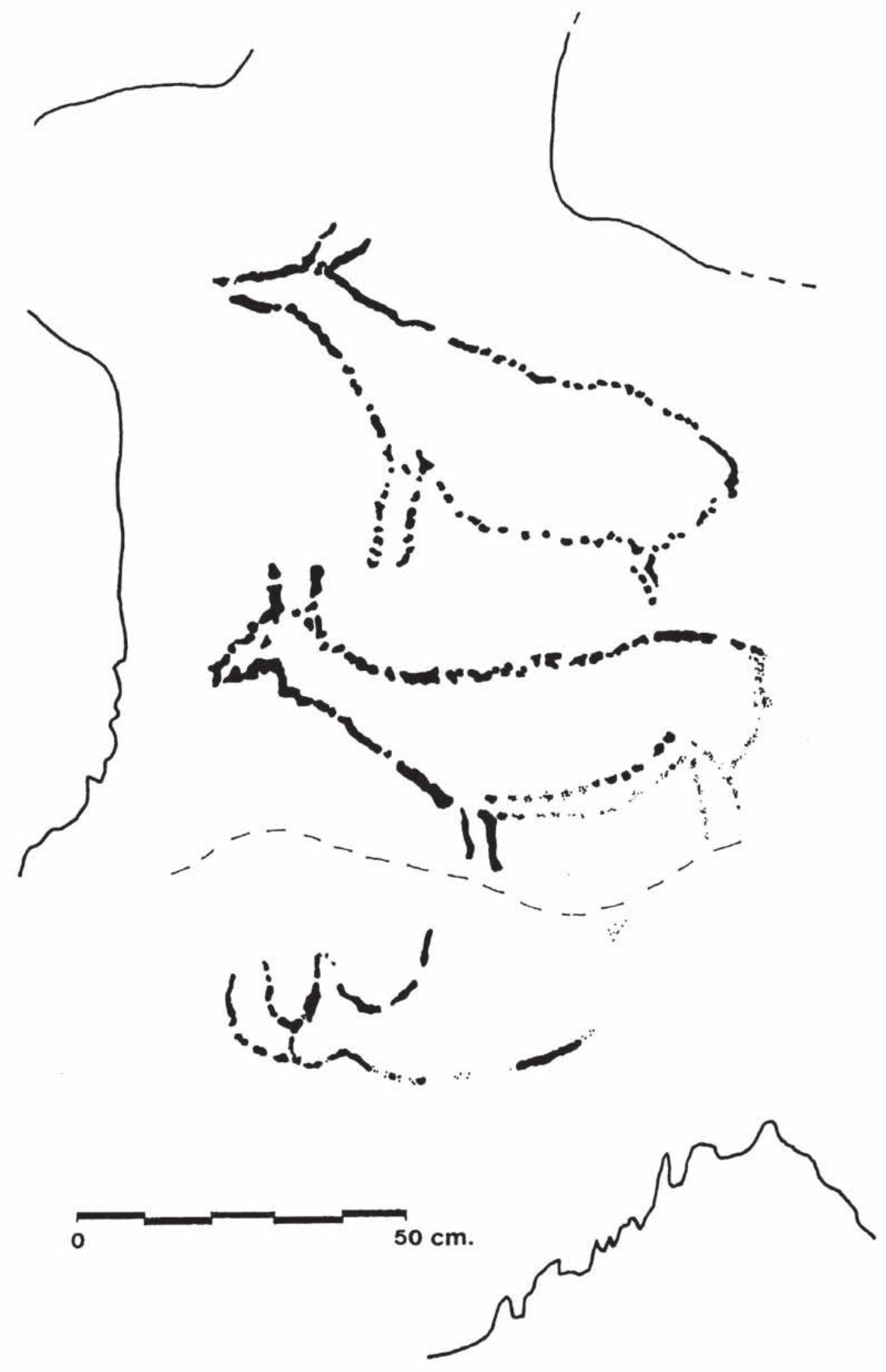

FIG. 8. - Proyección en plano de las figurasB.3 a B.5, correspondientes al segundo panel de la pared izquierda.

T. P., $1990, \mathrm{n}^{2} 47$ 
interpretar. L. máx.: 91; L. frontal: $16 \mathrm{~cm}$. Están desdibujadas, por frotación, las extremidades posteriores y zona ventral.

C.2. Cierva en rojo prácticamente completa, a falta de las extremidades anteriores. El contorno varia desde el trazo simple continuo - en la cabeza-, al tamponado vuxtapuesto, en ocasiones ligeramente ampliado (linea cérvico-dorsal, grupa, extremidad posterior y linea ventral). La línea pectoral también comienza con tamponado yuxtapuesto para finalizar con otro más separado. Aunque no tenemos total seguridad, creemos que esta figura se completó con grabados simples repetidos, muy finos, que delimitan la linea inferior de la cabeza y el morro.

A resaltar la indicación del ojo, la nuez muy marcada, dos orejas en prolongación de líneas frontal y cervical, 0 algunos restos de pintura en el interior, que podrían corresponder a una línea de despiece separando la cabeza del tronco. L. máx.: 67; L. frontal: 12.

C.3. Signo rectangular, de 8 por $24 \mathrm{~cm}$. en tinta plana roja.

C.4. Signo rectangular, de 8 por $22 \mathrm{~cm}$. en tinta plana roja.

C.a. Agrupados aqui algunos restos pintura roja que no conforman figuración inteligible, situados en la pared $C$, en las cercanías de las representaciones descritas. En primer lugar, una serie de trazos rojos, cortos y oblicuos, de unos $2 \mathrm{~cm}$. de longitud. A unos $40 \mathrm{~cm}$. del signo superior, y 34 del inferior, hay restos de pintura roja que parecen formar un motivo circular u oval, aunque es difícil precisarlo dado que la conservación de la pintura es muy mala. A unos $8 \mathrm{~cm}$. en diagonal hacia la derecha y hacia arriba hay restos de pintura roja en las oquedades de la pared. A unos $14 \mathrm{~cm}$. a la derecha y ligeramente por debajo de los anteriores hay otros restos de color más difusos.

Zona D. / (Panel séptimo) (Fig. 9.2 y Lám. VIb)

D.1. Cierva en rojo, completa si exceptuamos el tren posterior. Toda ella en tamponado yuxtapuesto, ligeramente ampliado en algunas zonas (así en la línea de la barbilla, prolongada para separar la cabeza del cuello). También presenta un despiece escapular, con restos de color desde la cruz hasta el tren anterior. Destaca por último la indicación del ojo en el centro de la cara, de la cola, separada de la linea de grupa, o dos orejas rectilíneas, separadas desde su inicio. L. máx.: 65 : L. frontal: 10.

D.a. Sobre la pared D se advierten numerosos restos de color, que en algún caso parecen corresponder a signos, hoy difícilmente recuperables. Los restos, que detallamos a continuación, se extienden por el lienzo a la izquierda de la cierva D.1.:

- un punto negro a $89 \mathrm{~cm}$. sobre el suelo y a $87 \mathrm{~cm}$. en diagonal desde el morro de cierva D.1.

- ligeramente por debajo de ese punto negro, se aprecian mínimos restos de color rojo, además muy difusos.

- A unos $45 \mathrm{~cm}$. más a la izquierda, y a 160 sobre el suelo, quedan restos de trazos de color rojo-anaranjado, que parecen formar un motivo cerrado, de forma ovalada, y con doble línea concéntrica, quizá con un saliente en diagonal hacia la derecha y arriba. Mide 14 por $12 \mathrm{~cm}$.

- A unos $130 \mathrm{~cm}$. de la cierva D.1., y a $7 \mathrm{~cm}$. en diagonal desde el punto negro, se aprecian restos de un trazo rojo horizontal, con restos muy perdidos de pintura a su alrededor.

T. P., $1990, \mathrm{n}^{2} 47$ 

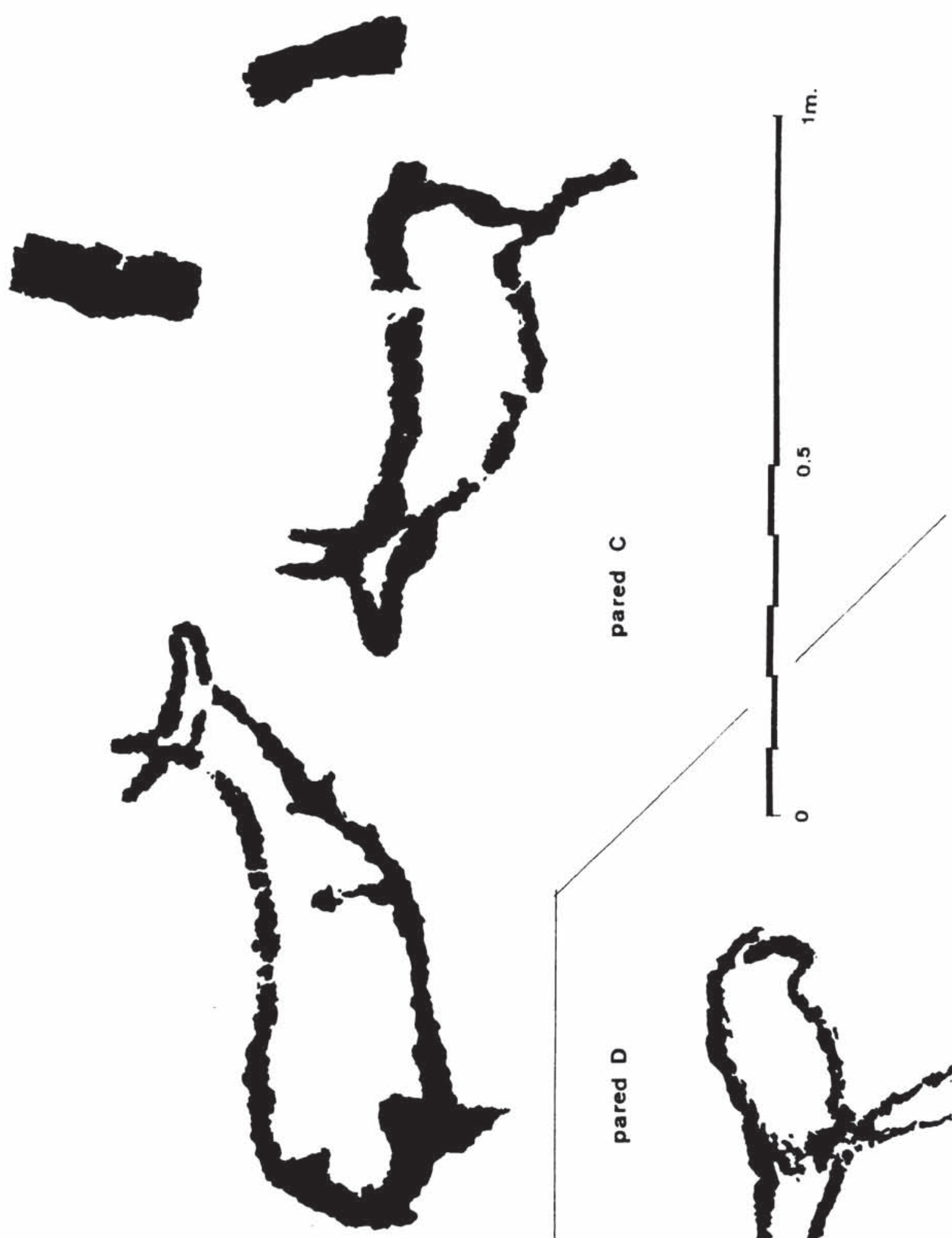

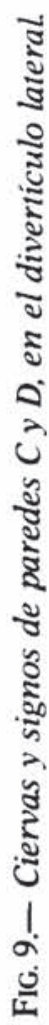

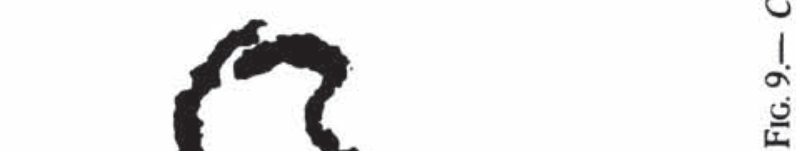

(c) Consejo Superior de Investigaciones Científicas

http://tp.revistas.csic.es Licencia Creative Commons 3.0 España (by-nc) 
- Siguiendo en la misma pared, a $68 \mathrm{~cm}$. en horizontal del punto negro, y a $76 \mathrm{~cm}$. del suelo, hay restos de pintura rojo-anaranjada que parecen corresponder a un motivo cerrado similar a los descritos como "vulvas".

- Unos $20 \mathrm{~cm}$. por debajo, y a la derecha del anterior, se parecian pequeños restos de pintura del mismo color, cubriendo una superficie de unos 12 por $12 \mathrm{~cm}$.

- Restos de pintura de color rojo más oscuro, bajo una grieta de la pared situada a por encima de los dos últimos restos descritos.

- A $18 \mathrm{~cm}$. a la izquieda del posible signo cerrado antes descrito, y a $109 \mathrm{~cm}$. sobre el suelo, se aprecian restos difusos de pintura roja oscura en un área de 8 por $5 \mathrm{~cm}$.

- Restos de trazos de color rojo oscuro, situados $38 \mathrm{~cm}$. a la izquierda del mismo signo, y entre 107 y $122 \mathrm{~cm}$. sobre el suelo.

- A unos $80 \mathrm{~cm}$. hacia la izquierda, y a unos $30 \mathrm{~cm}$. sobre el nivel de éstos últimos hay un trazo corto vertical, difuso, de $3 \mathrm{~cm}$.

- A unos $33 \mathrm{~cm}$. por encima, se aprecian restos de pintura de color rojo-anaranjado, quizá también parte de algún signo.

\section{Zona E}

E.1. Linea roja en taponado yuxtapuesto excepto en su parte derecha, donde las puntuaciones se separan. Pudiera interpretarse, quizá, como parte cérvico-dorsal de una figuración animal que nunca llegó a concretarse.

\section{Zona $F$}

F.a. En la zona terminal de la galería principal se aprecian manchas de color y algunos tracitos difusos sobre la pared derecha. Algunos metros más al interior, una vez sobrepasado un boquete que comunica con un conducto paralelo al principal, por su izquierda, pueden observarse también manchas y pequeños trazos de pintura roja sobre el techo.

\section{VALORACIONES DE CONJUNTO}

\subsection{Temas}

En Covalanas han sido documentadas 22 representaciones de animales, cinco signos seguros y dos probables y varias puntuaciones y trazos sueltos. Las figuraciones inventariadas corresponden a las siguientes especies: 18 ciervas, dos caballos, un bóvido y un posible reno. Con ciertas matizaciones que se incluyen a continuación, el bestiario paleolítico de Covalanas no desentona dentro del arte rupestre cantábrico.

Como puedẹ verse, la cierva predomina ampliamente (18 de las 22 figuras), lo que corresponde con su importancia en el resto de la región. Sobre un reciente recuento de 1.216 figuras animales identificables procedentes de 55 cuevas cantábricas, el Cervus representa el 33,7\% (24,2\% de ciervas y el resto de ciervos) (Moure Romanillo, 1988: 75-77).

T. P., $1990, \mathrm{n}^{\circ} 47$ 
Aunque a nuestro modo de ver la identificación de las ciervas no of rece ninguna duda más allá de lo razonable, conviene recordar algunas diferencias de criterio surgidas entre los primeros investigadores de Covalanas. H. Alcalde del Rio interpreta la escena del tercer panel como un grupo de lobos atacando a un caballo, en la que los cánidos salvajes corresponderian a las figuras A.14, A.15, A.16 (y tal vez la A.10) de nuestro inventario (Alcalde del Río, 1906: 44). Este fue sin duda un punto de desacuerdo con $\mathrm{H}$. Breuil y L. Sierra en Les cavernes de la Région Cantabrique, que de manera tan honesta como ecléctica incorporaron a su texto (Alcalde del Rio, Breuil y Sierra, 1911: 18).

El segundo cérvido de atribución controvertida es el indicado con la sigla A.9. La posibilidad de duda, también señalada por Alcalde del Rio, Breuil y Sierra (1911: 17-18), aunque presumiblemente debida al segundo, se debe a las proporciones y a algunos detalles de la figura, que animan a sugerir que se trate, más que de una cierva, de un reno durante la época de muda. En efecto, el canon y el contorno de la figura se aleja bastante del resto del panel y de la que la acompaña en la composición (número A.8): cuerpo macizo, hocico ancho y no apuntado, cuartos traseros angulosos, y línea de despiece escapular. No obstante, la propia variabilidad ya observada de las ciervas de Covalanas y la evidente asociación compositiva con otra figura cuya atribución no ofrece dudas, anima a mantener la clasificación como cierva. Hay que reconocer que los propios autores sugieren su clasificación como reno con bastantes reservas, apuntando que "sería preciso no exagerar la confianza en un dibujo hecho por artistas, sinceros sin duda, pero de una habilidad frecuentemente inconstantem. Con similar escepticismo se manifiestan I. Barandiarán en su síntesis sobre el reno en el arte rupestre cantábrico (Barandiarán Maestu, 1959: 14-16) y A. Leroi-Gourhan (1971: 277-279) en su obra clásica.

Pero sin duda el animal más discutido entre los representados en las pinturas de Covalanas es el señalado con el número B.1, sobre la pared izquierda de la cueva. Alcalde del Río, Breuil y Sierra no parecen tener dudas al clasificarlo como Bos, basándose en el perfil esbelto y alargado de la cabeza y en la posición de los cuernos, que parten de la frente dirigidos hacia adelante (Alcalde del Río, 1906: 44-45; Alcalde del Río, Breuil y Sierra, 1911: 20-21). La misma opinión «buey de formas ligeras" aparece años después en nuevos trabajos de H. Breuil (1952: 347). Por su parte, LeroiGourhan (1971: 277) lo presenta como un posible ciervo, ubicado en la parte anterior del Santuario (A en su plano) en asociación con una hilera formada por cuatro puntos.

Aunque el dibujo a mano alzada - presumiblemente realizado por $\mathrm{H}$. Breuil- no coincide exactamente con lo que hemos podido observar en la realidad, los dos trazos considerados como cuernos son un argumento en contra de nuestra interpretación: desde luego no pueden ser unas astas de cérvido, pero tampoco se encuentran en el lugar correspondiente a las de los bóvidos. Tanto si se trata de una especie como de la otra, esa posición tan atípica puede deberse a la limitación del espacio como consecuencia del accidente natural utilizado para completar la figura, y de las neoformaciones que se localizan sobre su cabeza.

Por nuestra parte, ya en el trabajo de documentación sobre la cueva de La Haza (Moure Romanillo, González Sáinz y González Morales, 1987: 80-81) aportamos una serie de argumentos a favor de su clasificación como reno (proporciones generales, cruz muy marcada, morro cuadrado, etc.). Además, el accidente natural utilizado con línea cérvico-dorsal y cuartos traseros incorpora una formación que sugiere la característica cola corta propia de los cérvidos, lo que parece excluir la interpretación de los primeros estudiosos de la cueva. También refuerzan nuestra opinión algunas convenciones propias de las representaciones pintadas de reno, como los despieces escapular y ventral. No hay que olvidar que la mayor parte de las referencias estilísticas sobre la especie proceden de representaciones de tipo figurativo analítico del estilo IV, y que son escasas las de episodios anteriores. Finalmente, uno de los argumentos más sólidos es el evidente paralelismo de ésta figura con el reno de La Haza, también adaptado parcialmente a la forma natural de la pared y que conserva además las inconfundibles astas de un cérvido. 
Los signos constituyen otro de los grupos de temas fundamentales de Covalanas, en este caso por su elevado valor cronológico. También aquí hay algunas discrepancias entre los diferentes autores que han estudiado la cueva. Básicamente podemos hablar de cuatro grandes grupos: signos cerrados en tinta plana, puntuaciones, trazos cortos y cerrados vacíos. Cuatro de los cerrados en tinta plana son claramente rectangulares característicos del estilo III, los señalados con los números A.4, A.17, C.3 y C.4. La misma técnica aparece en el referenciado como A.12 (extremo de la cola del caballo), aunque no se le pueda asignar una forma precisa.

Hay puntuaciones aisladas o en grupos en varios puntos de la galería: una hilera de cinco bajo el vientre del reno B.1, otros señalizados como B.a en el plano, un par en la galería final, próximo a la línea cérvico-dorsal de caballo E.1 y varios sueltos con diferentes ubicaciones.

Por sus posibles implicaciones en la datación del conjunto, conviene matizar alguna de las apreciaciones de A. Leroi-Gourhan referentes a un grupo de bastoncillos situados en la parte superior izquierda de la escena de las ciervas que rodean al caballo (Leroi-Gourhan, 1971: 110). La revisión efectuada sobre este tramo de pared indica, sin lugar a dudas, que se trata de un signo cuadrangular relleno de tinta plana ya señalado por Breuil, que corresponde con el número A.17 de nuestro inventario. El error de registro procede sin duda de una serie de precipitaciones de calcita que dividen verticalmente el signo, y que producen la impresión de que se trata de varias rayas de pintura roja independientes.

A. Leroi-Gourhan insiste en el diferente valor de las puntuaciones en función de su número, agrupación y ubicación. Es relativamente común la disposición en hilera bajo el vientre de ciertos animales, como sucede en la figura B-1, aunque en opinión el autor citado sea más frecuente en asociación con uros y caballos, o señalando el comienzo y el final de las áreas decoradas (LeroiGourhan 1971: 277-278). En otros yacimientos su disposición en zonas de bifuración o acceso a divertículos puede representar un cierto papel como referencia o indicativo topográfico (Balbín Behrmann y Moure Romanillo, 1981: 32).

Finalmente, y de nuevo siguiendo indicaciones de Leroi-Gourhan (1932: 58) la presencia de un pequeño signo en forma de " $\mathrm{V}$ " en el interior del dorse de la figura $\mathrm{B}-1$ tal vez pueda ser interpretada como una herida.

\subsection{Técnicas}

Covalanas presenta dos tipos de representaciones parietales, uno claramente paleolítico y otro de cronología indeterminada, ejecutados en pintura roja y negra respectivamente. El primero, que es el objetivo único del presente trabajo, ha sido presentado de manera constante en la bibliografía como un conjunto homogéneo caracterizado por el empleo de la técnica pictórica del tamponado, de la que, junto a la vecina cueva de La Haza, de alguna manera constituia el ejemplo máximo. El trabajo de documentación realizado ha permitido un análisis más detallado de los procedimientos pictóricos empleados y de su aplicación y repartición en las diferentes figuras. En algunas de ella se ha observado, además, sectores grabados que hasta ahora habían pasado desapercibidos.

Efectivamente, el color utilizado en las pinturas paleoliticas de Covalanas es siempre el rojo, aunque al menos con dos matices de tonalidad y con un procedimiento de ejecución menos homogéneo de lo que tradicionalmente se ha pretendido. La coloración roja intensa es la misma en todas las figuraciones de animales y en todos los signos en tinta plana, y se presenta en una tonalidad más suave, próxima al sepia, en el trazo que corta el cuello de la cierva número B-14 y en los signos y trazos D-1 y C-10.

Los procedimientos de aplicación de la pintura han sido aislados en cuatro grupos, que como veremos se utilizan en las distintas figuras y partes de las mismas de una manera no aleatoria:

- Tamponado yuxtapuesto. Se trata de una línea continua obtenida mediante la aplicación

T. P., $1990, \mathrm{n}^{\circ} 47$ 
sucesiva de tampones solapados unos con otros, de manera que se dibuja un trazo de perfil y límites irregulares en el que no pueden aislarse las puntuaciones.

- Tamponado discontinuo. Como su nombre indica consiste en la aplicación de líneas de puntos separados entre sí.

- Trazo contimuo obtenido mediante el convencional desplazamientos del instrumento utilizado para pintar. Ocasionalmente, este trazo aparece ampliado o ensanchado.

- Tinta plana, que es una extensión homogénea del color hacia el interior de la figura.

El grabado aparece de manera muy ocasional, siempre bajo la forma de trazo simple, único o repetido, en la línea de la terminologia al uso (Balbín Behrmann y Moure Romanillo, 1980: 102-106 y 1982: 77-78). Está presente en el contorno de la cabeza e inicio del cuello de las ciervas números A-3 y C-2, que significativamente son las únicas en que la parte anterior parece en tinta plana.

También de forma ocasional se aprovechan accidentes naturales de la pared para completar figuras o para sugerir el entorno de las mismas. En el posible reno señalado con la referencia B.1 se utiliza un reborde de la roca para representar el dorso e incluso en nuestra opinión la cola, que en caso de ser aceptada como tal sugiere claramente un cérvido. La pata delantera de la cierva A.1 coincide con una fractura vertical repasada con pintura, y en la pareja de ciervas formada por las figuras A. 8 y A.9, un grieta actúa como suelo natural. En la cierva A.l se ha hecho coincidir la línea del vientre con el límite entre dos zonas de pared con diferente textura y coloración.

Como se ha indicado, el empleo de los diferentes procedimientos de ejecución se adecúa a determinados esquemas que deben ser explicados. Ante todo, hay una clara diferencia en el tratamiento de las figuras de mayor tamaño (por encima de los $70 \mathrm{~cm}$.) y de las de dimensiones más reducidas. En las primeras se utiliza siempre una técnica mixta, con empleo de procedimientos más complejos que permiten una representación pormenorizada en la parte anterior del cuerpo, y en especial en la cabeza. Dentro de este primer grupo también hay un tratamiento diferente en tres parejas de ciervas (A.1-A.2, A.8-A.9 y B.3-B.4) por un lado, y en el caballo A.11 y el reno B.1 por otro.

Todas las figuras indicadas miran hacia la izquierda, tanto las situadas en la pared derecha, y por ello orientadas hacia el fondo de la cueva, como la de la pared izquierda, que consiguientemente apuntan hacia la entrada. Las cabezas han sido realizadas en tamponando yuxtapuesto, incorporando en ocasiones una ampliación o prolongación del trazo por detrás del maxilar: por el contrario, en el resto del cuerpo se emplea el tamponando discontinuo. El tratamiento más cuidado del tren anterior y de los detalles de la cabeza es una constante en el arte rupestre paleolítico de diferentes épocas, incluso en los estilos más evolucionados. Resulta especialmente frecuente en las figuras de mayor tamaño, sin que siempre pueda explicarse por limitaciones en el campo manual. A título de ejemplo puede aludirse a los grabados de la «Galería de los caballos» de la cueva de Tito Bustillo (Balbín Behrmann y Moure Romanillo, 1980): las figuras más pequeñas incorporan detalles de la totalidad del cuerpo, mientras que alguna de las mayores, en concreto el único bóvido del bloque, presenta una cabeza pormenorizada, con ojo, lacrimal, ollares y boca, que contrasta con un tren posterior bastante simplificado.

En el caso que nos ocupa, el tamaño y accesibilidad de las parejas de ciervas de la pared derecha excluyen que el diferente tratamiento de cada parte del cuerpo se deba a limitaciones en el campo manual, que podia ser perfectamente controlado desde el suelo original de la cueva. La ejecución de las cabezas y la orientación ya indicadas indica al menos tres cosas: que todas estas figuras fueron diseñadas de izquierda a derecha, que se siguió un esquema compositivo constante en que lo fundamental era el tratamiento de la cabeza, y que el pintor o pintores eran diestros.

Muy distinto desde un punto de vista técnico es el procedimiento seguido en las otras dos figuras mayores, el caballo y el posible reno. Aunque en ambos casos las cabezas incorporan todos los detalles (ojo, despiece de maxilar, bocal, no se observa un desequilibrio importante con respecto al resto del cuerpo. Los cuartos traseros del caballo, con ambas patas diferenciadas en plano y la 
cola, se realizaron en trazo continuo ampliado y en tinta plana. En el reno los despieces escapular y ventral reflejan un especial interés por la reproducción fidedigna de algunos de los elementos identificativos del animal.

Las figuras menores utilizan, por el contrario, un único procedimiento de ejecución y se disponen con diferentes orientaciones - a la derecha, a la izquierda o incluso invertidas-, con independencia de que estén completas o no.

El empleo de técnicas mixtas es ocasional. En los cuartos traseros de la cierva A.9 se observa la superposición de una línea de tamponado discontinuo a un trazo ancho y bien definido, lo que no refuerza precisamente la teoría tradicional sobre evolución de técnicas. Como ya se ha indicado, el grabado de trazo simple se asocia a la tinta plana en la cabeza y el inicio del cuello de otras dos ciervas, la que ocupa la posición central en el segundo panel (número A.3) y una de las del divertículo C (número C.2).

\subsection{Composición y articulación del espacio}

Uno de los más antiguos tópicos relativos al arte rupestre paleolitico es la ausencia de cualquier intención compositiva, presentándolo como una suma o yuxtaposición de figuras sin relación entre sí.

Sin embargo, si entendemos composición como la suma ordenada de varios elementos para intentar reproducir un determinado efecto, es obvio que se trata de un esquema presente en el arte del Paleolitico Superior. Una visión superficial de alguno de los principales yacimientos (Lascaux, Rouffignac, Font de Gaume, etc.) hace resaltar la presencia de escenas de carácter narrativo en el sentido más clásico, a las que hay que sumar otros numerosos conjuntos figurativos en que los temas se disponen de acuerdo con ciertas pautas que intentan reproducir sucesos de la realidad: superposiciones sincrónicas como recurso de perspectiva, composiciones "estilísticas" formadas por grupos de cabezas de animales, etc.

En el caso concreto de Covalanas, ya Leroi-Gourhan señalaba el carácter ideal de la caverna, con un desarrollo en corredor en el que los hombres quisieron materializar algo coherente mediante un esquema compositivo que buscaba la representación en dos planos sucesivos (Leroi-Gourhan, 1971: 80 y 122). En nuestra opinión la existencia de ese esquema general es cuando menos defendible. No obstante, a un nivel más detallado podemos hablar de varias escenas con un menor número de componentes, organizadas en parejas y en grupos. la existencia real de asociación entre las figuras mencionadas se apoya en cuestiones de indole topográfica (yuxtaposición estrecha), estilística (la coincidencia entre ellas de los caracteres de diseño antes mencionado), de técnica y de tamaño.

Las escenas formadas por una pareja de animales se disponen en hilera en la parte superior de los paneles de la pared derecha (figuras A.1-A.2, A.8-A.9 y A.13-A.14), a dos alturas en yuxtaposición amplia estrecha en la pared izquierda (figuras B.4 y B.5), y afrontadas en el divertículo indicado con la letra $\mathrm{C}$ en el plano (figuras C.1 y C.2). Las parejas de la galería principal responden al esquema simple con tamponado yuxtapuesto en la cabeza y discontinuo en el resto del cuerpo, mientras que las del divertículo emplean técnicas mas complejas, con tintas planas, despieces y empleo del grabado en uno de los casos. Tal vez sea indicativo el hecho de que a las dos ciervas afrontadas de la zona $\mathrm{C}$ les falten las patas anteriores. En las composiciones de la galería principal el esquema que se sigue es el de dos líneas paralelas y oblicuas, mientras que en el divertículo $\mathrm{C}$ podemos hablar de composición simétrica a partir de un eje inclinado.

Los grupos en que interviene un número mayor de figuras aparecen en los paneles clásicos más conocidos de Covalanas: el de las ciervas con la cabeza levantada o vuelta del segundo panel y las que rodean al caballo en el tercero. En el primero de los paneles parece evidente una intención compositiva, con varios individuos volviendo o levantando la cabeza como si existiese algún motivo de atención. Es importante subrayar que entre los diferentes elementos que forman parte de esta 
composición se encuentran representadas todas las técnicas descritas en Cuvalanas: tamponado convencional, tamponado discontinuo, tinta plana y grabado, lo que es un testimonio más del carácter sincrónico de todas sus pinturas.

El tercer panel, en que se encuentra el caballo, es de interpretación más compleja. A pesar de ser figuras incompletas, la disposición de las ciervas sugiere una cierta animación; lo difícil es buscar el trasfondo narrativo, si es que existe, del grupo. La interpretación de Alcalde del Río, de una escena que representa un grupo de lobos atacando un caballo, podría dar una explicación al panel, pero tal identificación no parece defendible. Excluida ésta, sólo restan tres posibles respuestas: que las figuras no tengan relación entre si (o que la tengan las ciervas y no el caballo), que se trate de la traducción de un suceso real, o que una vez más estemos ante algo simbólico. Existe la posibilidad de que ciervos y caballos aparecan ocasionalmente juntos en la naturaleza, y la diferencia de escala explicarse por el tradicional recurso de perspectiva.

Sólo en un caso puede hablarse de figuras en posición inverosímil: el único bóvido de la cueva, referenciado con el número B.2. Como se ha descrito, se encuentra con las patas dirigidas hacia arriba. La dirección vertical de la pared excluye que la posición sea indiferente a la hora de contemplarla, por lo que sin duda se trata de algo intencional, aunque no estemos en situación de interpretarlo.

\subsection{Cronología}

Apenas conocemos conjuntos parietales donde la impresión de sincronía sea tan inmediata como en Covalanas. Tanto por la organización topográfica de las figuraciones, como por las técnicas, convenciones y estilo empleados, parece claro que estamos ante un conjunto realizado en breve período de tiempo, si no de una sola vez.

Respecto a su cronología, apenas hemos encontrado nuevos elementos de juicio en nuestro trabajo, que esencialmente se orientaba a la documentación exhaustiva del conjunto. Por ello, mantenemos en lo esencial el esquema cronológico que proponíamos al estudiar el vecino yacimiento de La Haza (Moure, González Sáinz y González Morales 1987: 89-91). En ese trabajo considerábamos un momento intermedio en el desarrollo temporal del "Estilo III" en la región Cantábrica, tanto para La Haza como para Arenaza y Covalanas, quizá inmediatamente anteriores a aquélla. Estas tres cavidades se consideraban también ligeramente más antiguas que Pasiega $\mathrm{A}$, con figuras animales de estilo algo más depurado, y signos tal vez más avanzados (cuadrangulares en arco conopial).

En relación a la secuencia industrial, proponíamos la asociación de estos conjuntos al Solutrense Cantábrico en base sobre todo a los restos industriales de algunos de ellos.

Tan sólo contamos ahora con un mínimo indicio nuevo, valorable en términos cronológicos: los grabados que rematan la tinta plana de la cabeza de al menos dos ciervas de Covalanas. Es un tratamiento idéntico al que encontramos en algunas figuras de Pasiega A (precisamente las más complejas técnica y formalmente, también en tinta plana), y ello nos obliga a relativizar aún más el valor de nuestras conclusiones cronológicas, o a destacar la enorme continuidad que encontramos en la zona central y occidental de la región, en algunos procedimientos técnicos, temas y tratamiento, desde aproximadamente los inicios del Solutrense (c. 20.000 BP) hasta el final Magdaleniense Inferior clásico (c. 14.400 BP), quizá el período más espectacular, y de mayor personalidad artística de ese área. 


\section{BIBLIOGRAFIA}

Al.cal.DF Dfl. Rio. H. (1906): Las pinturas y grabados de las cavernas prehistoricas de la Provincia de Santander. Santander, Imp. de Blanchard y Arce.

Al.calde del. Rio, H.; Brfill., H. y Sif:Rra, L. (1911): Les Cavernes de la Region Cantabrique. Mónaco.

Apelláiviz, J. M. (1982): El arte prehistórico én el Pais Vasco y sus vécinos. Bilbao, Desclé de Brouwer.

Bai.bin Behrmann, R. DE y Moure Romanillo, A. (1980): "La galeria de los Caballos de la Cueva de Tito Bustillo", en Altamira Symposium, Madrid, Ministerio de Cultura, pp. 85-117.

- (1981): Las pinturas y grabados de la Cueva de Tito Bustillo: El sector oriental. Valladolid, Universidad de Valladolid, Studia Archaeologica.

- (1982): «El panel principal de la Cueva de Tito Bustillom, Ars Praehistorica, l, pp. 47-97.

Barandiaran Maestu, 1. (1969): «Representación de renos en el arte paleolitico español», Pyrenae, $V$, pp. 1-37.

CABrÉ, J. (1915): Al Arte Rupestre en España. Regiones Central y Oriental. Madrid, CIPP, (Memoria $\mathrm{n}^{\circ}$ 1).

González Morales, M. y Moure Romanillo, A. (1989): "Las Cuevas de Ramales de la Victoria (Cantabria)", Revista de Arqueologia, 95, pp. 10-17.

Lerol-Gourhan, A. (1971): La Prehistoire de l'art occidental. 2.a edición, París, Mazenod.

- (1983): Los primeros artistas de Europa. Madrid, Encuentro.

Moure Romanillo, A. (1987): "Introducción al arte rupestre paleolítico cantábrico", Revista de Arqueologia: Número monográfico "Arte Rupestre en España" pp. 30-37.

- (1988): "Composition et variabilité dans l'art pariétal paléolithique cantabrique", L'Anıhropologie, 92-4, pp. 73-86.

Moure Romanillo, J. A.; González Morales, M. y González Säinz, C. (1984-85): "Las pinturas paleolíticas de la Cueva de La Fuente del Salin (Muñorrodero, Cantabria)". Ars Praehistorica, 3-4, pp. 13-23.

Moure Romanillo, A.; González Sainz, C. y González Morales, M. (1987): "La cueva de La Haza (Ramales, Cantabria) y sus pinturas rupestresn, Veleia, 4, pp. 67-92.

Sierra, L. (1908): "Notas para el Mapa Paleoetnográfico de la Provincia de Santander», Actas del I Congreso Español de Naturalistas (Madrid, 1908), pp. 103-117. 


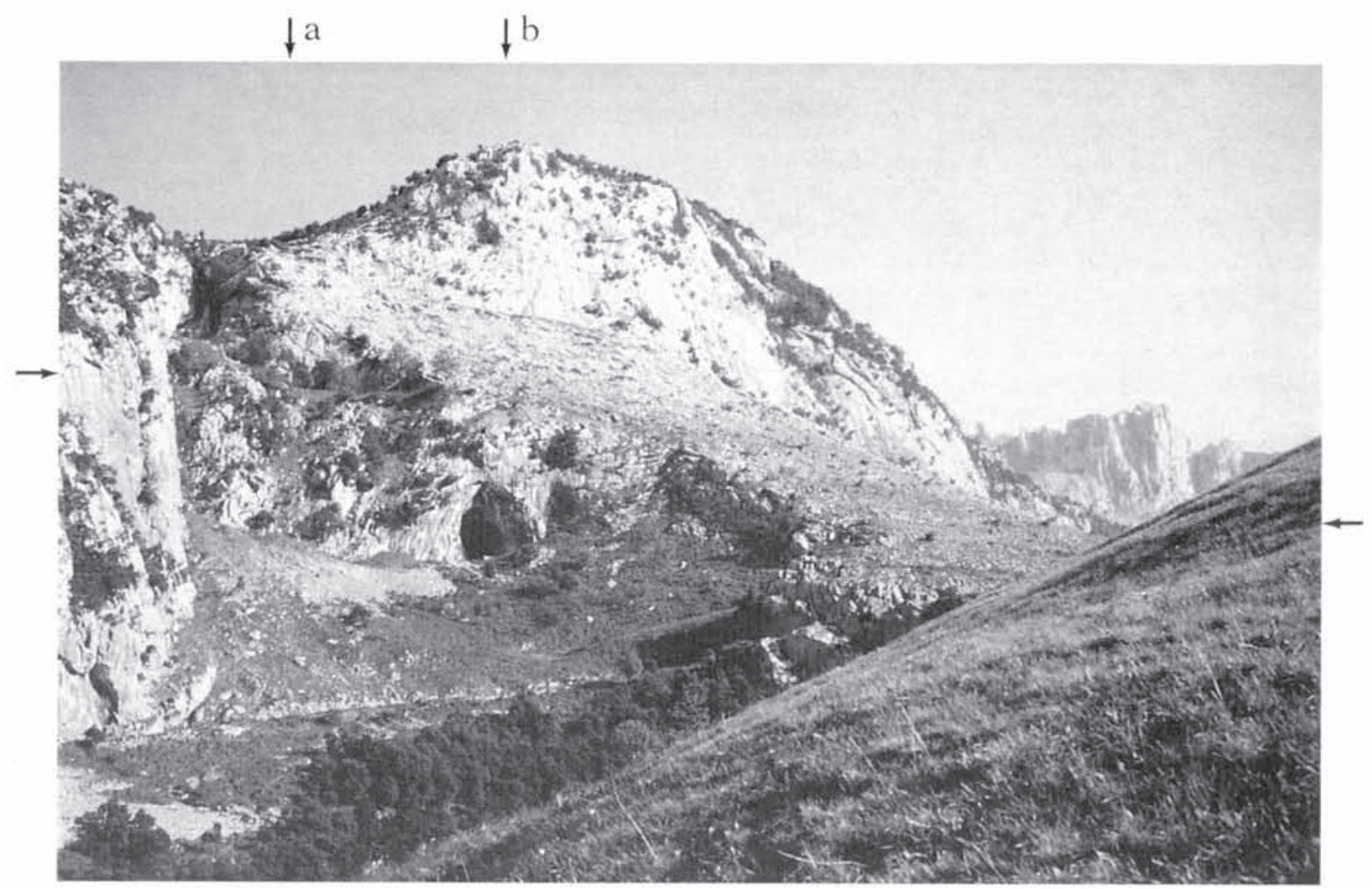

a.- Vista de la cara Oeste del monte Pando con indicación de las entradas de la cueva de Covalanas (a) y El Mirón (b).

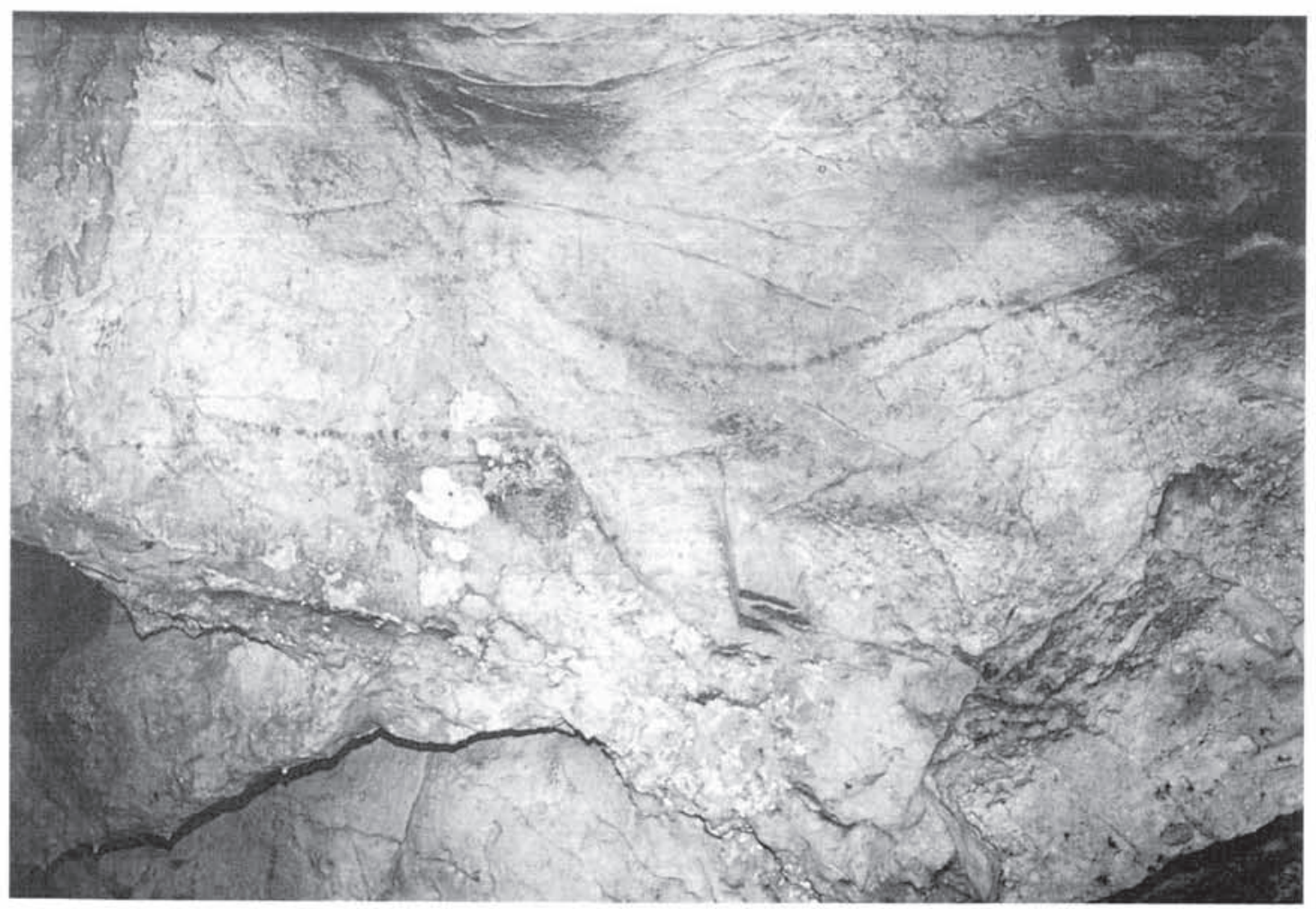

b.-Ciervas A.l y A.2.

T. P., 1990, $\mathrm{n}^{\circ} 47$ 


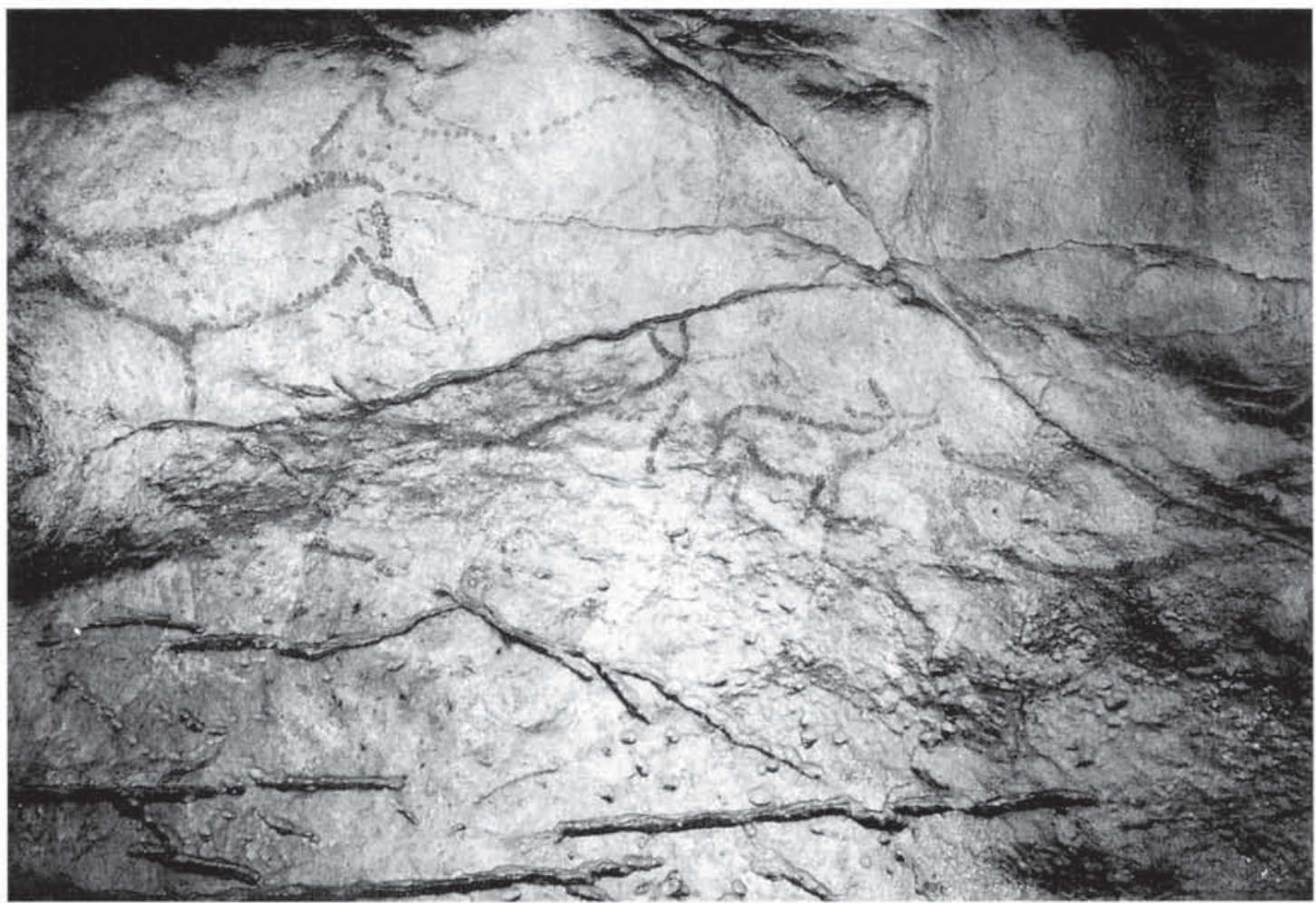

a.- Ciervas y restos de signo A.3 a A.9.

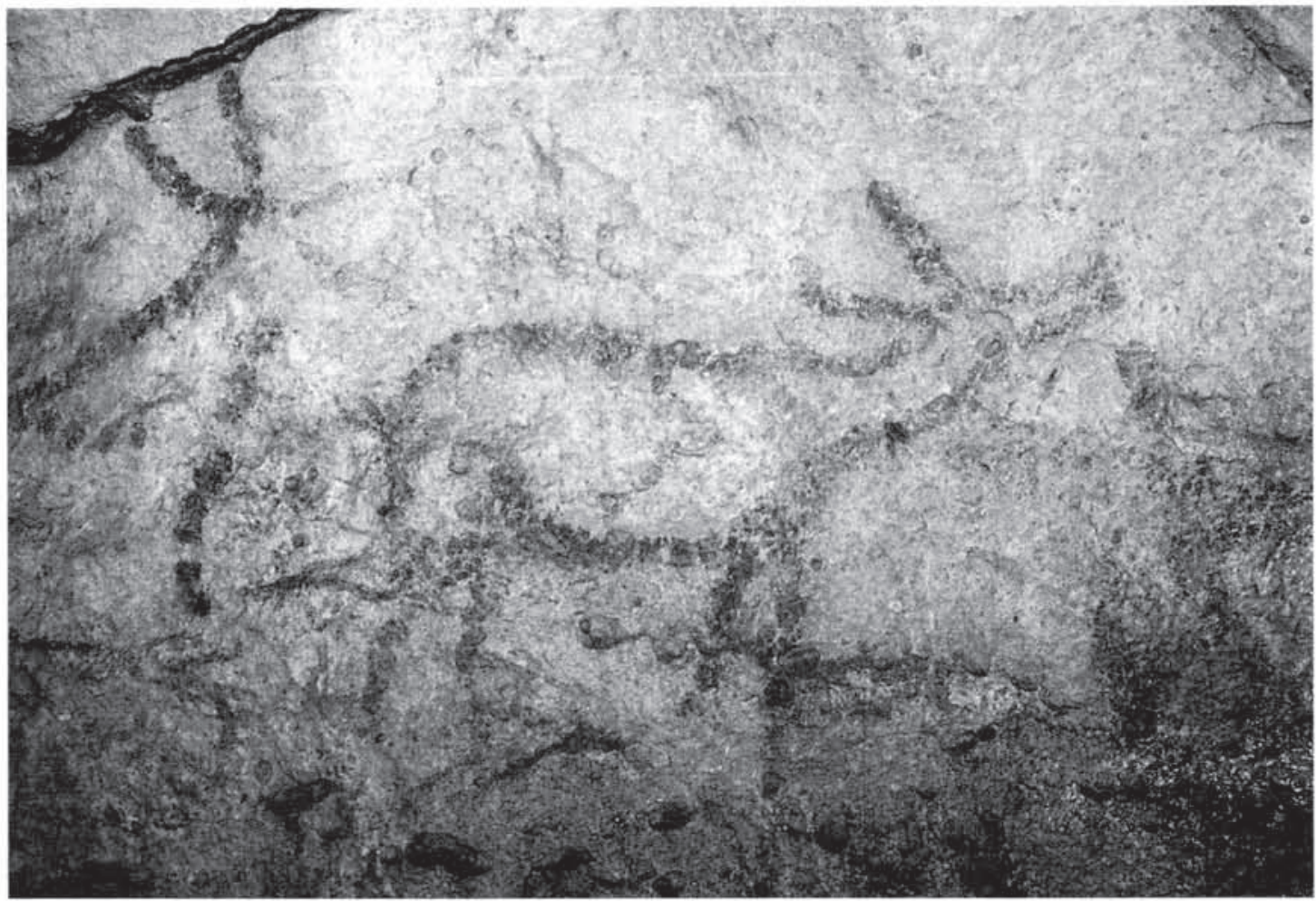

b.- Detalle de la cierva A.5 y figuras vecinas.

T. P., 1990, no 47 


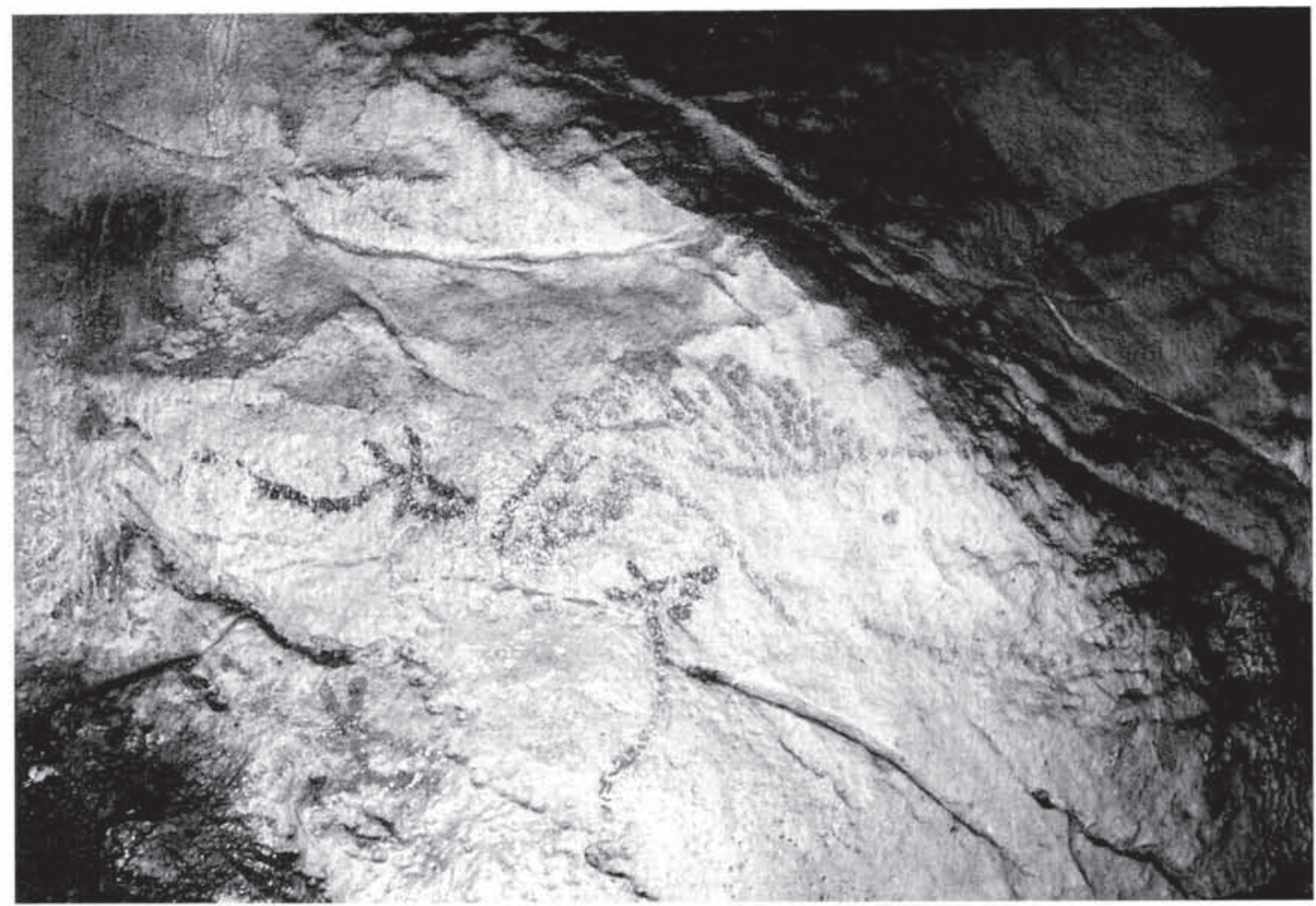

a.-Caballo, ciervas y signos A.10 a A.17.

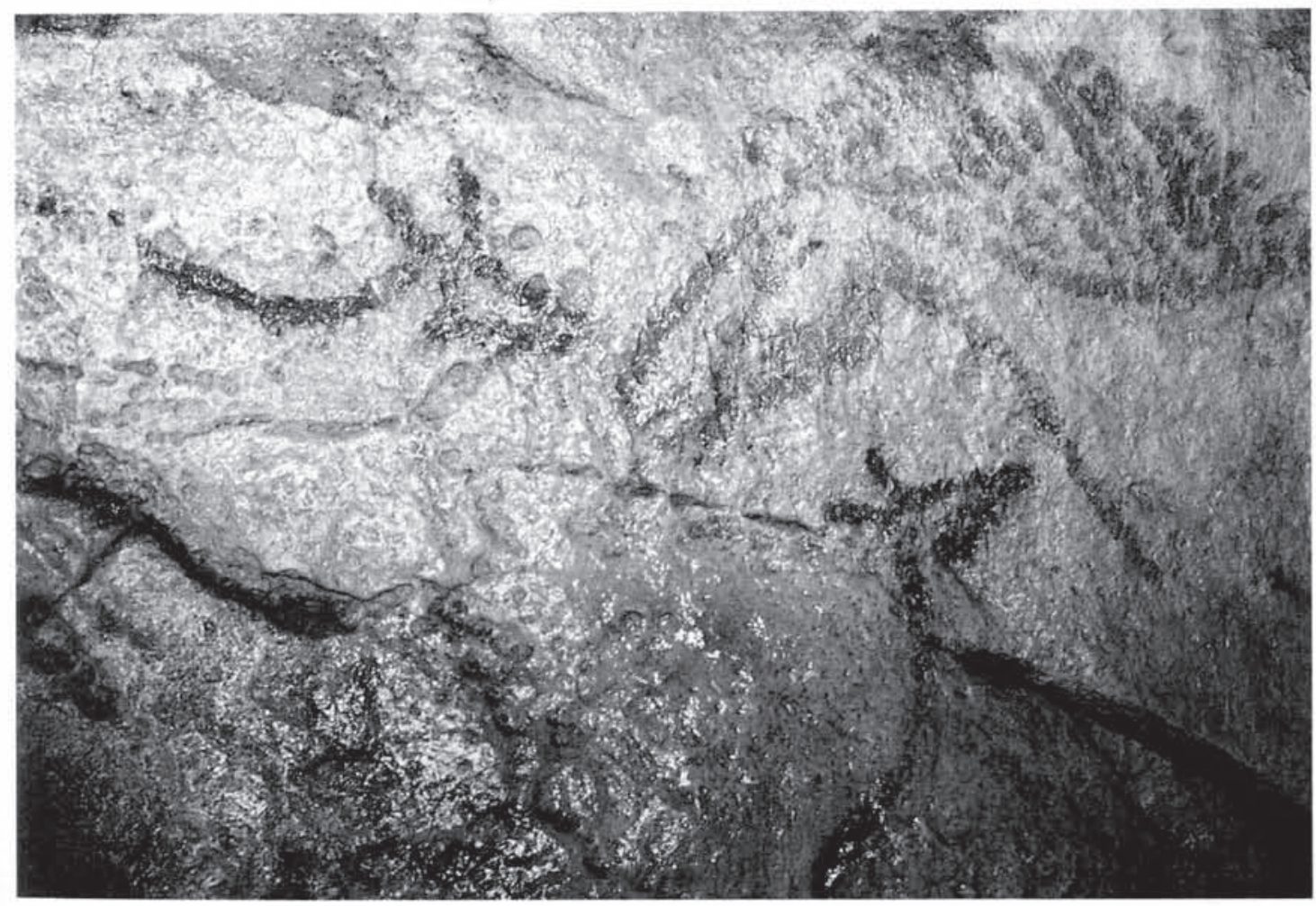

b.- Detalle del caballo A.11 y ciervas A.13 a A.15.

T. P., $1990, \mathrm{n}^{9} 47$ 


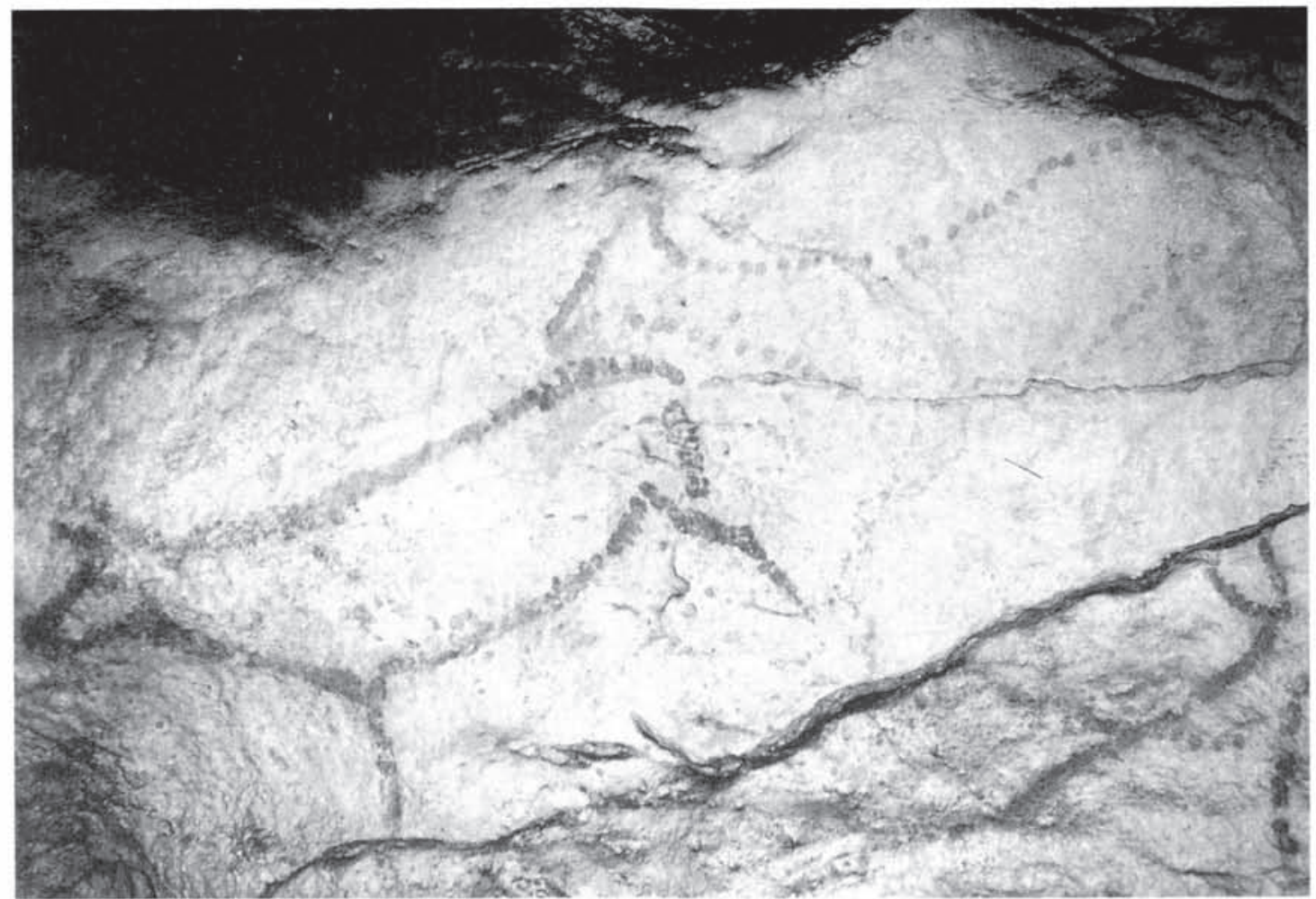

a.-Ciervas A.8 y A.9.

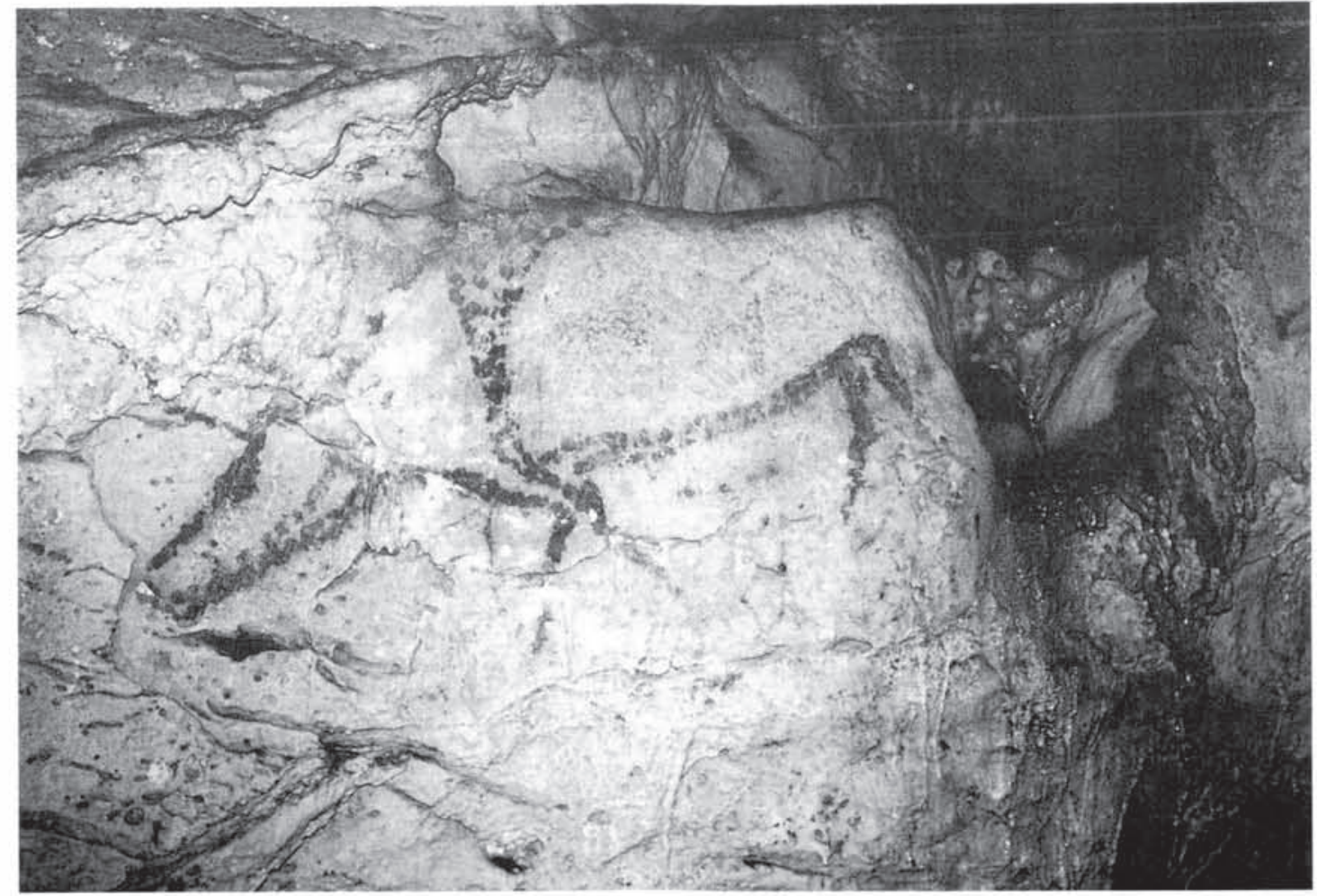

b.- Probable figura de reno y linea de puntos B.I y B.2.

T P $1990 \quad n \div 47$ 


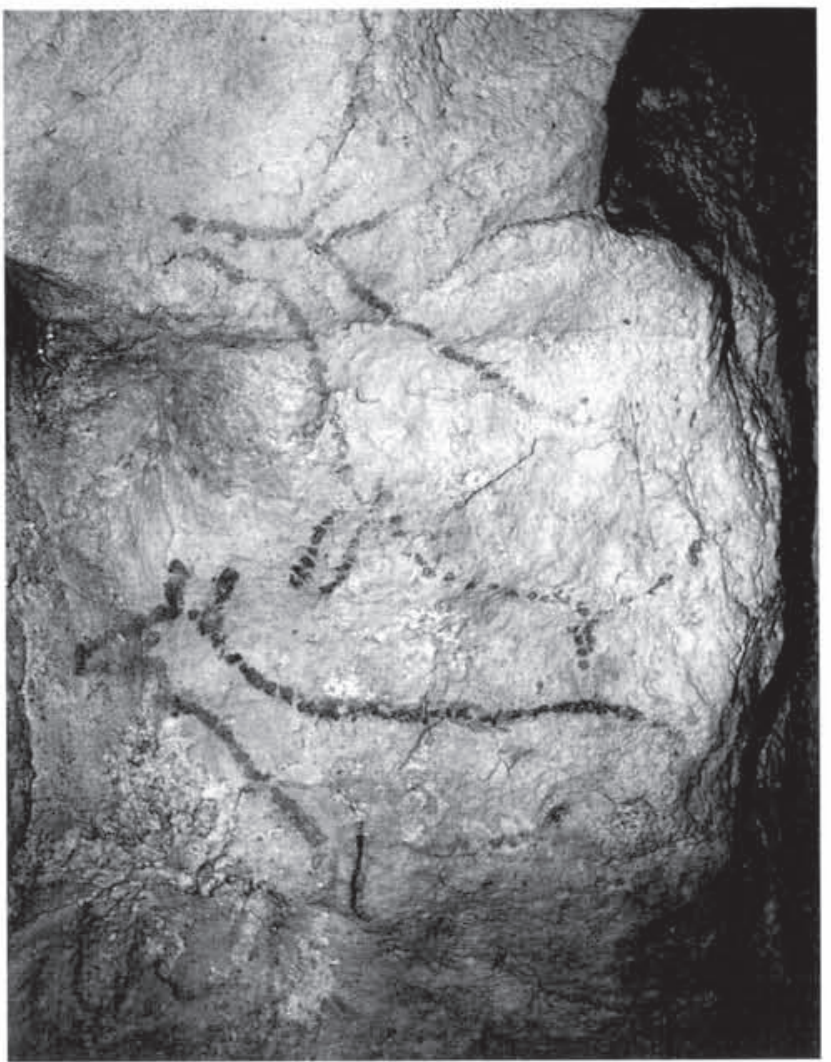

a.- Posible bovido (B.3) y ciervas (B.4 y B.5).

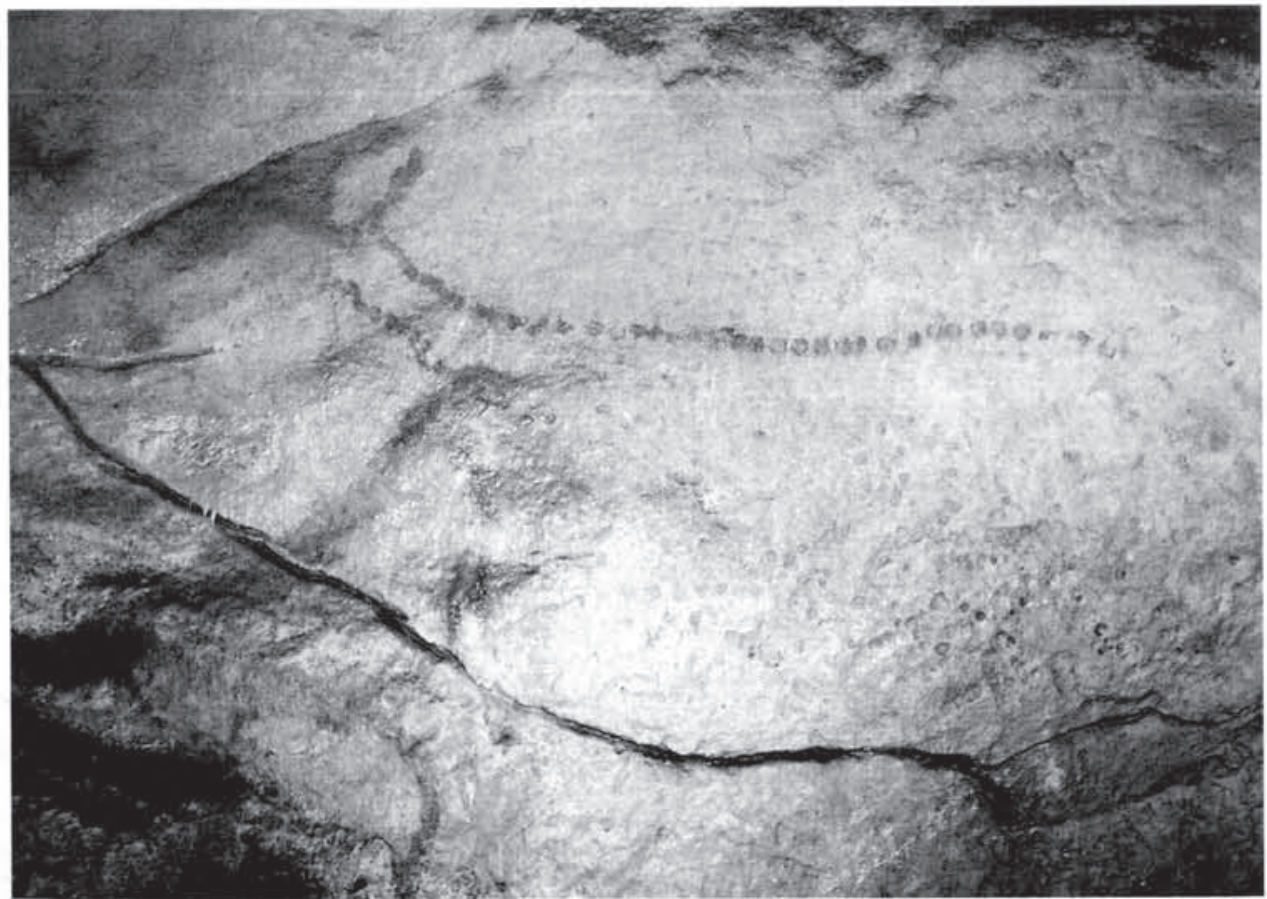

b.-Cierva A.10.

T. P., 1990, nº 47 


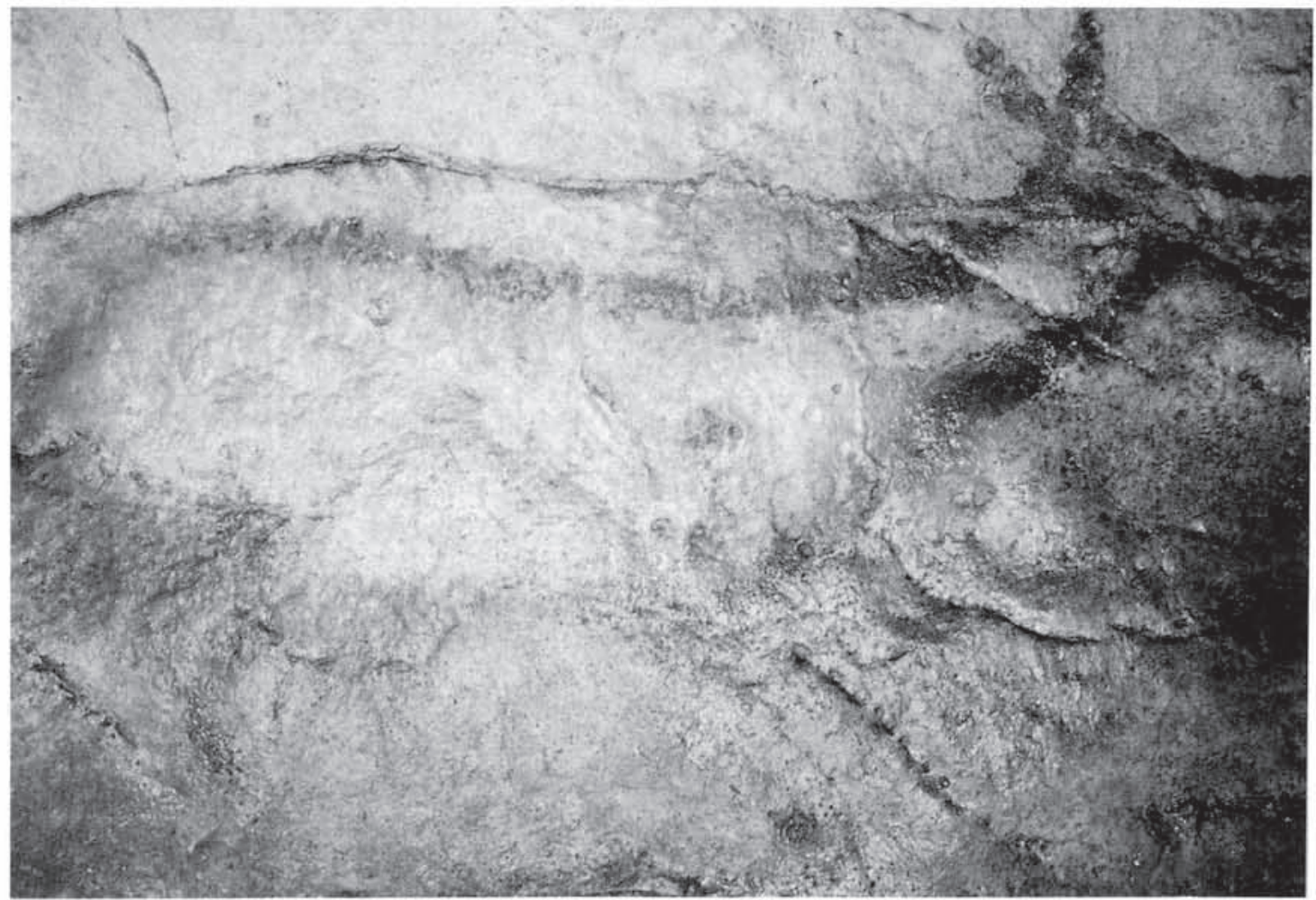

a.- Cierva C-1.

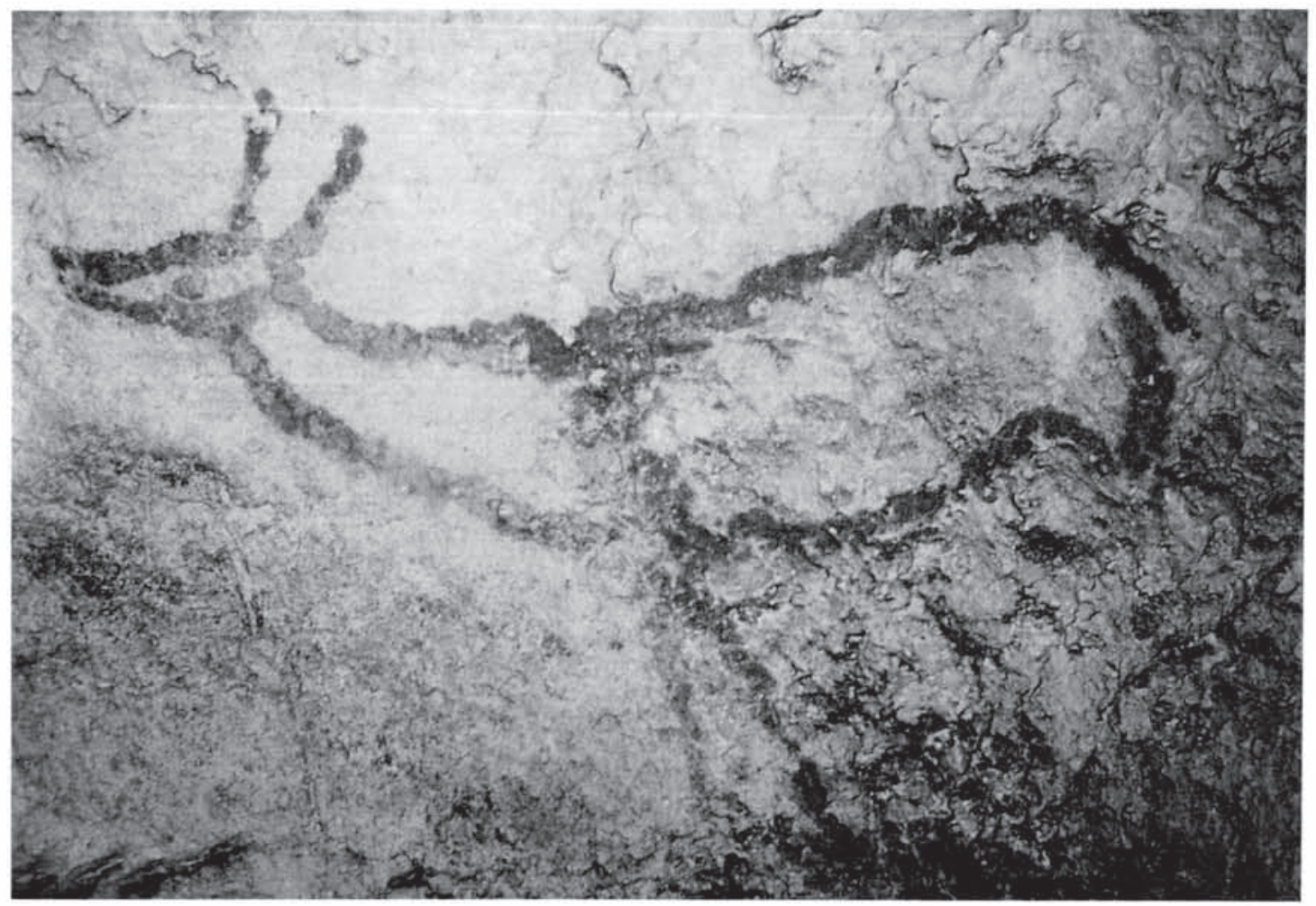

b.- Cierva D-I.

T. P., 1990, no 47 